\title{
Enhancement of Ca Current in the Accessory Radula Closer Muscle of Aplysia californica by Neuromodulators That Potentiate Its Contractions
}

\author{
V. Březina, ${ }^{1}$ C. G. Evans, ${ }^{1}$ and K. R. Weiss ${ }^{1,2}$ \\ 'Department of Physiology and Biophysics and the ${ }^{2}$ Fishberg Research Center in Neurobiology, Mount Sinai School of \\ Medicine, New York, New York 10029
}

A major goal of neuroscience is to identify the neural and cellular mechanisms of behavior and its plasticity. Progress toward this goal has come particularly from work with a small number of tractable model preparations. One of these is the simple neuromuscular circuit consisting of the accessory radula closer (ARC) muscle of the mollusk Aplysia californica and its innervating motor and modulatory neurons. Contraction of the ARC muscle underlies a component of Aplysia feeding behavior, and plasticity of the behavior is in large part due to modulation of the amplitude and duration of the contractions of the muscle by a variety of modulatory neurotransmitters and peptide cotransmitters, among them the small cardioactive peptides (SCPs), myomodulins (MMs), and serotonin (5-HT). We have studied single dissociated ARC muscle fibers in order to determine whether modulation of membrane ion currents in the muscle might underlie these effects. First, we confirmed that the dissociated fibers were functionally intact: just as with the whole ARC muscle, their contractions were potentiated by $5-\mathrm{HT}$ and $\mathrm{SCP}_{\mathrm{B}}$ and potentiated as well as depressed by $M_{A}$, and their CAMP content was greatly elevated by $5-H T, S C P_{A}$ and $S C P_{B}$, and to a lesser extent by $M M_{A}$ and $M M_{B}$. Next, using voltage-clamp techniques, we found that two ion currents present in the fibers were indeed modulated. The fibers possess a dihydropyridine-sensitive, high-threshold " $L$ "-type $C a$ current. This current was enhanced by the modulators that potentiate ARCmuscle contractions-5-HT, $S C P_{A}$ and $S C P_{B}$, and $M M_{A}$ and $M_{B}$ - but not by buccalin ${ }_{A}$, a modulator that does not act directly on the ARC muscle. All of the potentiating modulators, as well as elevation of CAMP in the fibers by forskolin or a cAMP analog, maximally enhanced the current about twofold and mutually occluded each other's effects. Since the $\mathrm{Ca}$ current supplies $\mathrm{Ca}^{2+}$ necessary for contraction of the muscle, the enhancement of the current is a good candidate to be a major mechanism of the potentiation of the contractions. In the following article we report that the modulators also, to different degrees, activate a distinctive $K$ current and thereby depress the contractions. Net potentia-

\footnotetext{
Received Sept. 23, 1993; revised Jan. 19, 1994; accepted Jan. 27, 1994

This work was funded by NIMH (MH36730 to K.R.W. and K21 MH00987 to V.B.), the McKnight Foundation (K.R.W.), the Revson Foundation (V.B.), and the Whitehall Foundation (V.B.).

Correspondence should be addressed to Dr. Vladimír Březina, Department of Physiology and Biophysics, Box 1218, Mt. Sinai School of Medicine, 1 Gustave L. Levy Place, New York, NY 10029.

Copyright $\odot 1994$ Society for Neuroscience $0270-6474 / 94 / 144393-19 \$ 05.00 / 0$
}

tion or depression then depends on the balance between the relative strengths of the modulation of the two ion currents.

[Key words: neuropeptides, cotransmitters, neuromodulators, smooth muscle, membrane ion channels, calcium current, cAMP, mollusk, Aplysia]

Much of our understanding of the fundamental neural and cellular mechanisms of behavioral plasticity has come from work with a relatively small number of tractable model preparations, many of them invertebrate. One of these is a simple neuromuscular circuit in the mollusk Aplysia californica consisting of the accessory radula closer (ARC) muscle, its two motor neurons B15 and B16 (Cohen et al., 1978), and a modulatory metacerebral cell (MCC) that also innervates the muscle (Weiss et al., 1978). The ARC-muscle circuit generates a component of $A p l y$ sia feeding behavior, and extensive study over the past 15 years has revealed dynamic changes in the physiology of the circuit that go far toward explaining plasticity observed in the behavior (reviewed by Kupfermann et al., 1989; Weiss et al., 1992).

To feed, Aplysia protrudes from its mouth a hand-like organ called the radula, which it uses to grasp food and draw it into the esophagus. Contraction of the ARC muscle closes the radula around the food. However, the ARC is only one of many buccalmass muscles that must contract coordinately to oroduce functional biting and swallowing. Preservation of the functional integrity of these behaviors even as their frequency and amplitude change requires coordinated changes in the parameters of the contractions. In particular, stronger and faster biting when the animal encounters tougher food or during food-induced arousal reflects coordinated potentiation of the amplitude and frequency of contractions of the ARC and other muscles (Weiss et al., 1992). Such changes are likely to be implemented simultaneously at multiple levels within the nervous system (Weiss et al., 1978; Kupfermann et al., 1989; cf. Calabrese, 1989; Watson and Groome, 1989), but one site of major plasticity is clearly at the very end of the output motor pathway, at the final neuromuscular junction. There, it has recently become apparent, the plasticity is in large part due to appropriate release of modulatory neurotransmitters in addition to the "classical," mediating transmitter. In the case of the ARC muscle, the two motor neurons $\mathrm{B} 15$ and $\mathrm{B} 16$, which initiate contractions of the muscle by releasing $\mathrm{ACh}$ (Cohen et al., 1978), also contain a number of peptide cotransmitters belonging to several different families that modulate several parameters of the contractions. B15 contains the small cardioactive peptides $\mathrm{SCP}_{\mathrm{A}}$ and $\mathrm{SCP}_{\mathrm{B}}$ (Cropper 
et al., 1987a), B16 contains a variety of myomodulins (best characterized are $\mathrm{MM}_{\mathrm{A}}$ and $\mathrm{MM}_{\mathrm{B}}$ : Cropper et al., 1987b, 1991), and both neurons contain the buccalins (best characterized is buccalin $_{\mathrm{A}}$ : Cropper et al., 1988, 1990a). Yet another modulator, serotonin (5-HT), is released from the purely modulatory MCC neurons (Weiss et al., 1978). Several of the peptide cotransmitters have now been shown to be released when the motor ncurons are fircd at physiological frequencics recorded in freely feeding animals (Whim and Lloyd, 1989; Cropper et al., 1990b; Vilim et al., 1991). Some of the modulators primarily potentiate the ARC-muscle contractions, others either potentiate or depress them, depending on the concentration, and yet others have depressive effects only. Thus, 5-HT, the SCPs, and some of the MMs (e.g., $\mathrm{MM}_{\mathrm{B}}$ ) strongly potentiate the amplitude of the contractions (and/or the tension developed) and at the same time speed their relaxation rate (Weiss et al., 1978; Lloyd et al., 1984; Ram et al., 1984a; Cropper et al., 1988, 1991). MM $_{\mathrm{A}}$, in contrast, has these effects only at low concentrations; above about $10^{-7}$ $\mathbf{M}$, it strongly depresses the contractions (Cropper et al., 1987b, 1991). (Some depression is seen also with very high concentrations of the potentiating modulators: E. C. Cropper, personal communication.) Finally, the buccalins have purely depressive effects (Cropper et al., 1988, 1990a; Vilim et al., unpublished observations). Another difference between the modulators is in their probable primary site of action within the neuromuscular junction. The buccalins most likely feed back to inhibit the presynaptic release of $\mathrm{ACh}$, as they are able to depress only contractions evoked by motor neuron stimulation (Cropper et al., 1988, 1990a). All of the other modulators, in contrast, while perhaps not without some presynaptic effects (e.g., Vilim et al., 1992), powerfully modulate also contractions elicited by direct application of exogenous $\mathrm{ACh}$ to the muscle, suggesting that their principal action is postsynaptic, on the ARC muscle itself (Weiss et al., 1978; Lloyd et al., 1984; Ram et al., 1984a; Cropper et al., 1991). It seems likely that the potentiation of the amplitude of contractions by 5-HT, the SCPS, and the MMs, of the ARC as well as probably other buccal-mass muscles (e.g., Lotshaw and Lloyd, 1990), is responsible for much of the increased strength of biting during food-induced arousal (Weiss et al., 1992). Further, the apparently counterproductive co-release of modulators with opposing effects may be explained if the combination of their effects maximizes control over the duration of the relaxation phase of the contractions, which is likely to be critical to precise synchronization of contractions of different muscles and thus production of functional behavior (see Weiss et al., 1992). As similar complex local neuromodulatory networks appear to operate in other invertebrate as well as vertebrate neural circuits (reviewed by Calabrese, 1989; Kupfermann, 1991), further study of the modulation in the ARC-muscle system will undoubtedly continue to reveal principles of general significance. In particular, the preparation provides an opportunity to investigate, within the broader context of their physiological and behavioral roles, the cellular mechanisms of action of a variety of mutually interacting neurotransmitters and modulators.

This work concerns the cellular mechanisms by which the postsynaptic modulators-the SCPs, the MMs, and 5-HT-act directly on the ARC muscle. Several lines of evidence suggest that they may exert at least some of their actions via cAMP (see Discussion). Beyond this, however, very little is known. Since ample precedent exists for ion-channel activity as a determinant of muscle contractility (see the Discussion of this and the fol- lowing article, Březina et al., 1994d), we have begun to test the hypothesis that the modulators alter the contractions of the ARC muscle by modulating its membrane ion currents.

Previous work in muscle electrophysiology has shown how difficult it is to address such a question satisfactorily in the whole muscle. Whole muscles typically present severe access barriers to experimental solutions and drugs, electrical junctions between fibers prevent rigorous voltage clamp, and the possibility exists for confounding effects of transmitters secondarily released from nerve terminals within the muscle (reviewed by Lieberman et al., 1987). These problems can be avoided by studying isolated single fibers enzymatically dissociated from the muscle. Dissociated fibers generally retain most of their native characteristics, even such complex functions as modulation of contractions and membrane ion currents (Lieberman et al., 1987; see further references in the Discussion). Since the whole ARC muscle is likely to suffer from many of the same experimental drawbacks as other whole muscles (see Cohen et al., 1978), we have similarly chosen to study its dissociated fibers, while endeavoring to maintain conditions as near in vivo as possible to ensure applicability of our results to the whole muscle and eventually the physiology of the behaving animal. In this article, we confirm that the dissociated ARC muscle fibers indecd remain functionally intact by the most demanding, and important, test: they still exhibit the modulation of contractions whose mechanisms we are investigating.

In three previous articles (Březina et al., 1994a-c), we studied the electrophysiology of the unmodulated ARC muscle fibers and characterized their major ion currents. One of these is a dihydropyridine-sensitive, high-threshold "L"-type Ca current. In this article we show that the postsynaptic modulators enhance this current, and propose that this is a major mechanism by which they potentiate ARC-muscle contractions. In the following article (Březina et al., 1994d), we describe a second modulated current, a $\mathrm{K}$ current that, we suggest, depresses the contractions.

Abstracts of this work have appeared previously (Březina et al., 1991, 1992).

\section{Materials and Methods}

As outlined in the introductory remarks, the experiments in this and the following article (Březina et al., 1994d) continued work begun in the earlier series of three articles (Březina et al., 1994a-c), where most of the methods used have already been described in detail. Here we review them only briefly, therefore, with emphasis on points particularly significant for the present experiments.

Dissociated ARC muscle fibers. ARC muscles were dissociated into their constituent single muscle fibers by collagenase treatment. Although most experiments were done on fibers $1-3 \mathrm{~d}$ old, all of the modulatory effects described here and in the following article could also be obtained immediately after dissociation, showing that they did not require time in the dissociated state to become expressed and therefore most likely reflected processes operating in situ in the intact ARC muscle (see Discussion).

Contractions of single fibers. One end of the experimental fiber was sucked into a large-bore fire-polished glass pipette. (The suction could then usually be released, as the fibers tended to adhere tightly immediately on contact with the glass-borosilicate thin-wall glass from World Precision Instruments, New Haven, CT-that we used to make the pipettes as well as all our electrophysiological recording electrodes.) The fiber was held suspended in a fast-flowing stream of solution whose force stretched the fiber straight and also perhaps helped ensure complete relaxation after a contraction. The length of the fiber could then simply be read off a calibrated micrometer graticule in the microscope eyepiece or, in some experiments, from $35 \mathrm{~mm}$ photographs taken at the appropriate times (see Fig. $1 A$ ). This manual way of measuring the fiber was 
adequate for the purposes of the initial series of experiments described here (see Results), which required measurement only before and at the peak of a contraction, and the contractions were sufficiently slow (usually around $1 \mathrm{sec}$ to peak) to follow. To induce the contractions, $10 \mu \mathrm{M}$ (in a few experiments, up to $1 \mathrm{~mm}$ ) ACh made up in the same artificial seawater flowing past the fiber (normal ASW; see below) was puffed from a second large-bore pipette positioned upstream so that the whole length of the fiber was exposed to the ACh. In early experiments we confirmed the trajectory of the puffed solution by visualizing it with $0.1 \% \mathrm{w} / \mathrm{v}$ fast green dye (Fig. $1 \mathrm{~A}$ ). The puffs were most often $1 \mathrm{sec}$ long, but sometimes adjusted as short as $100 \mathrm{msec}$ or as long as $3 \mathrm{sec}$ to obtain reproducible contractions of moderate size (we aimed for initial unmodulated contractions of $5-25 \%$ of the relaxed length of the fiber, but some experiments began with somewhat smaller or larger contractions; Fig. $1 \mathrm{Ba}$ ). The puffs were given regularly every $60 \mathrm{sec}$ while the modulators (see below) were added to the bath ASW flowing past the fiber.

Assay of CAMP in the dissociated fibers. A sufficient number of ARC muscles was dissected (from 100-250 gm animals) to allow one muscle per experimental treatment (i.e., each point in Fig. 2, $a$ or $b$ ). The muscles were dissociated as usual, the dissociated fibers pooled, concentrated by a brief spin, and then divided again into the same number of fractions. Each fraction was treated with the appropriate concentration of modulator, drug, or vehicle for either 2 or 5 min (see Fig. 2 caption) at room temperature, and then heated to $90^{\circ} \mathrm{C}$ for $5 \mathrm{~min}$, homogenized, and finally centrifuged at $13,000 \times g$ for $5 \mathrm{~min}$. The supernatant was assayed for cAMP using a ${ }^{125}$ I-cAMP radioimmunoassay kit (Amersham). The protein content of the supernatant was measured using the spectrophotometric BCA Protein Assay (Pierce).

Electrophysiological techniques: current and voltage clamp of single fibers. For recording, fibers were immobilized in agarose gel. This provided considerable mechanical stability of the fibers in the face of rapid solution flow, relatively fast solution exchange, yet brought the fibers close to the surface so that only the very tip of the recording electrode(s) needed to be immersed in the solution. Typical gel volume in the experimental chamber was 10-30 $\mu \mathrm{l}$, covered by an approximately equal volume of solution. During recording the chamber was always continuously perfused at a constant rate, in early experiments between 0.5 and $1.5 \mathrm{ml} / \mathrm{min}$ but later up to $5 \mathrm{ml} / \mathrm{min}$. The gel did not appear to hinder appreciably access to the embedded fibers by substances added to the perfusing solution. In earlier tests (Březina et al., 1994a), effects expected to be exerted directly on the membrane, such as depolarization of the fibers by high- $\mathrm{K}^{+}$solution or block of $\mathrm{Ca}$ and $\mathrm{K}$ currents by simple inorganic ions, were substantially complete within $30-90 \mathrm{sec}$ at perfusion rates around $1 \mathrm{ml} / \mathrm{min}$ (at the slowest rates, occasionally up to $3 \mathrm{~min}$; see Fig. $7 \mathrm{Aa}$ ) and $10 \mathrm{sec}$ at $5 \mathrm{ml} / \mathrm{min}$ (see Fig. $3 \mathrm{Bb}$ ), not very different from the likely rates of mixing of similar volumes of solution unconstrained by gel. In the experiments described in this and the following article, most effects of drugs and even the peptide modulators (some with molecular weights over 1000 ) had broadly similar time courses (see Figs. $3 B b, 7 A a$ ). Since these could therefore be assumed to be determined primarily by the speed of bath exchange, only major departures from them are noted as intrinsic properties of the effects themselves.

The aim of the experiments in this and the following article was to obtain a complete overview of ion-channel modulation in the ARC muscle fibers under conditions as closely resembling those in vivo as possible. We therefore chose to employ sharp intracellular microelectrodes, rather than the more disruptive whole-cell clamp technique, to avoid possible washout of any labile cytoplasmic constituents (e.g., ATP, GTP, cAMP, and other second-messenger pathway components) that might be required for the modulation. A few experiments involved only voltage recording (see Fig. 5), but most fibers were voltage clamped with either the two-electrode or the discontinuous single-electrode technique. Earlicr tcsts (Bŕczina et al., 1994a) suggestcd that even relaxed fibers could usually be adequately space clamped, and clamp quality was presumably further improved when the fiber contracted (in most experiments in this article, the $\mathrm{Ca}$ or $\mathrm{Ba}$ current was studied with repetitive, strongly depolarizing voltage steps, the first few of which were usually sufficient to contract the fiber profoundly and irreversibly, whether in $\mathrm{Ca}^{2+}$ - or $\mathrm{Ba}^{2+}$-containing solution) or was intentionally precontracted (prior to many of the experiments in the following article).

The voltage steps used to elicit the $\mathrm{Ca}$ or $\mathrm{Ba}$ current were generally either short, $200 \mathrm{msec}$ given every $20 \mathrm{sec}$ (e.g., Fig. $3 B$ ), or long, $5 \mathrm{sec}$ every $60-180 \mathrm{sec}$ (e.g., Figs. $3 A, 7 A$ ). These intervals between steps were in most cases many times longer (cf. Fig. 6 of Březina et al., 1994c) than required for the $\mathrm{Ca}$ or $\mathrm{Ba}$ current to recover from current-dependent inactivation even when the current was considerably enhanced by the modulators. Unless complete $I-V$ relations were to be obtained, the steps were routinely from -90 to $0 \mathrm{mV}$. In most experiments, we converted raw $\mathrm{Ca}$ - or Ba-current records into the net currents by subtracting from them the residual currents (primarily leakage current together with the capacitive-current transients, but in some fibers not treated with 4-AP also some residual unblocked " $A$ " $K$ current: see Březina et al., $1994 \mathrm{c}$ ) that remained after all extracellular $\mathrm{Ca}^{2+}$ or $\mathrm{Ba}^{2+}$ was replaced with $\mathrm{Co}^{2+}$ at the end of the experiment (e.g., Figs. $3 B, 7 A$ ). However, none of our conclusions about the $\mathrm{Ca}$ or Ba current or its modulation depended on such subtraction, as the residual currents were typically much smaller than the $\mathrm{Ca}$ or Ba current (with steps to $0 \mathrm{mV}$ in healthy fibers, no more than $10-15 \%$ of its amplitude), and were not altered by the modulators (see Fig. 3Ac).

Solutions, drugs, modulators. Normal ASW, used to handle and store the fibers and throughout the contraction experiments and cAMP assays, contained (in mM) $460 \mathrm{Na}^{+}, 10 \mathrm{~K}^{+}, 11 \mathrm{Ca}^{2+}, 55 \mathrm{Mg}^{2+}, 602 \mathrm{Cl}^{-}$, and 10 HFPES buffer ( $\mathrm{pH}$ 7.6). However, all of the electrophysiological experiments described in this article were done with substituted variants of this solution in which all of the $\mathrm{Na}^{+}$was replaced with $460 \mathrm{~mm}$ tetraethylammonium $\left(\mathrm{TEA}^{+}\right)$to make the solution identified as $\mathrm{Ca}$ / TEA ASW, all of the $\mathrm{Ca}^{2+}$ further replaced with $11 \mathrm{mM} \mathrm{Ba}^{2+}(\mathrm{Ba} / \mathrm{TEA}$ $\mathrm{ASW}$ ) or $\mathrm{Co}^{2+}(\mathrm{Co} / \mathrm{TEA} \mathrm{ASW})$, and $10 \mathrm{~mm}$ 4-aminopyridine (4-AP) often added to give $\mathrm{Ca} /, \mathrm{Ba} /$ or $\mathrm{Co} / \mathrm{TEA} / 4$-AP ASW.

TEA-Cl was obtained from Sigma, Aldrich, Kodak, and Fluka; Bay K 8644, forskolin, and 1,9-dideoxyforskolin from Calbiochem; Ro 201724 from Biomol; $\omega$-conotoxin GVIA, $\omega$-conotoxin MCVII, $\omega$-agatoxin IVA, ritanserin, ketanserin (+)-tartrate, methysergide maleate, and cyproheptadine hydrochloride from RBI (Research Biochemicals International, Natick, MA); all other chemicals and drugs (apart from the modulators; see below) were from Sigma or Fisher. All drugs were applied by bath perfusion. Nifedipine, Bay K 8644 , forskolin, 1,9-dideoxyforskolin, and Ro 20-1724 were made up at $100 \mathrm{~mm}$ in dimethyl sulfoxide (DMSO) before being dissolved in the bath solution, which therefore, since these drugs were typically used at $10-100 \mu \mathrm{M}$, also contained $0.01-0.1 \% \mathrm{v} / \mathrm{v}$ DMSO in those experiments. Up to $0.25 \%$ DMSO alone had no effect on the Ba current (Březina et al., 1994c); furthermore, the same DMSO concentration present in the drug-containing solution was often added also to control solutions. Ritanserin stocks were similarly made up in methanol, and cyproheptadine in ethanol. In some experiments with the conotoxins and agatoxin, solutions were supplemented with $1 \mathrm{mg} / \mathrm{ml}$ bovine serum albumin to saturate possible adhesion sites in the perfusion tubing.

The modulators used were serotonin (5-hydroxytryptamine, 5-HT) hydrochloride or creatinine sulfate (from Sigma), the small cardioactive peptides $S C P_{A}$ and $S C . P_{B}$, the myomodulins $M_{A}$ and $M_{B}$, and buccalin $_{A}$. The peptides were each obtained from one or more of Peninsula (Belmont, CA), Applied Biosystems (Foster City, CA), and Nuros (San Jose, CA), with no obvious difference between batches of the same peptide from these different sources. All of the modulators were applied by bath perfusion.

The contraction and electrophysiological experiments were done at room temperature, usually between $20^{\circ} \mathrm{C}$ and $24^{\circ} \mathrm{C}$.

\section{Results}

Modulation of contractions of single dissociated ARC muscle fibers

Our first concern was to demonstrate that the phenomenon whose origins we wished to study, namely, the postsynaptic modulation of ARC-muscle contractions by the SCPs, MMs, and 5-HT, was still present in the dissociated fibers. To this end, we measured the amplitude of contractions of single fibers, as the percentage by which the fiber shortened, under conditions likely to permit near-isotonic contraction, in response to a standard brief puff of the natural contraction-inducing transmitter ACh (Fig. $1 A$; for further details, see Materials and Methods). In this initial series of experiments we did not attempt to measure the relaxation rate of the contractions; automated methods 
A

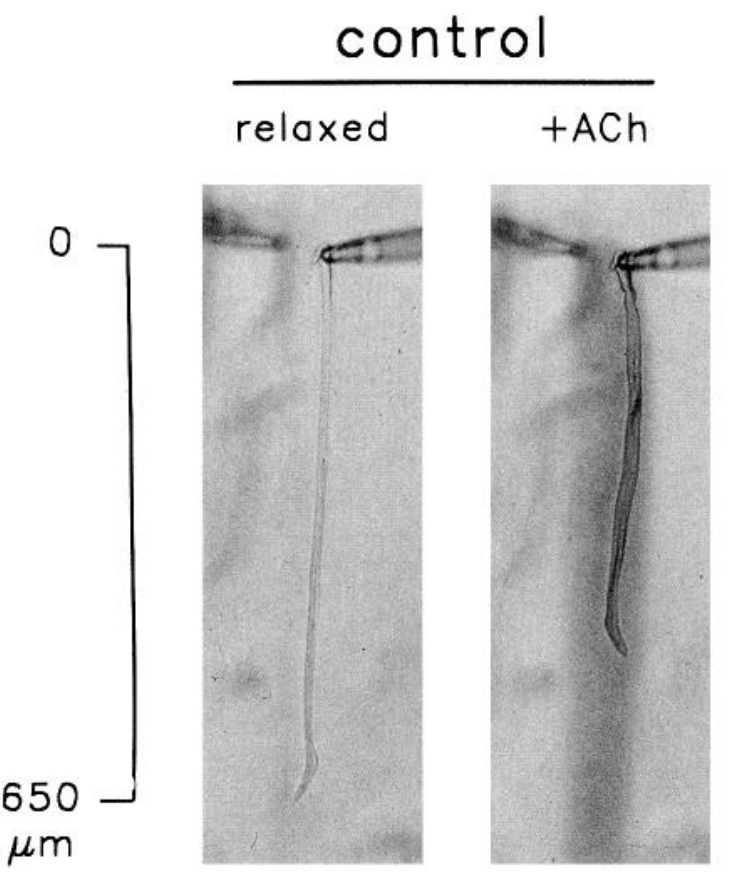

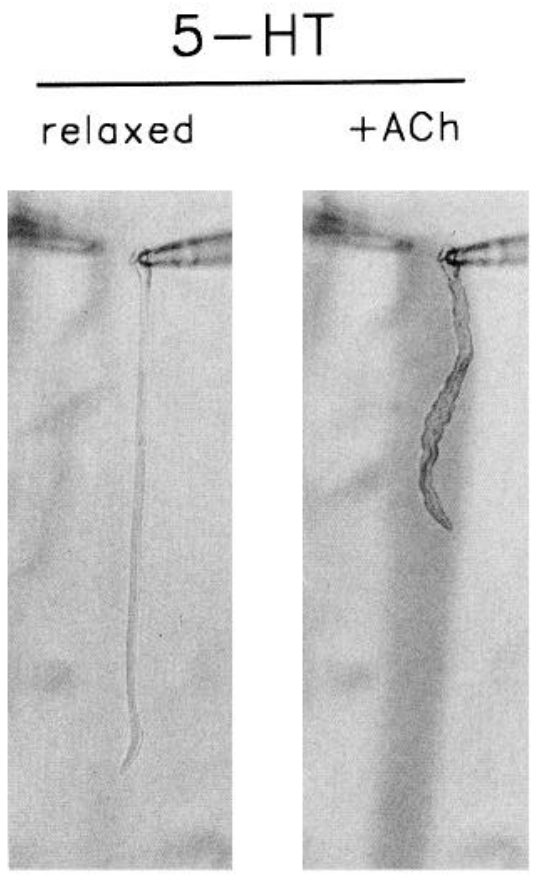
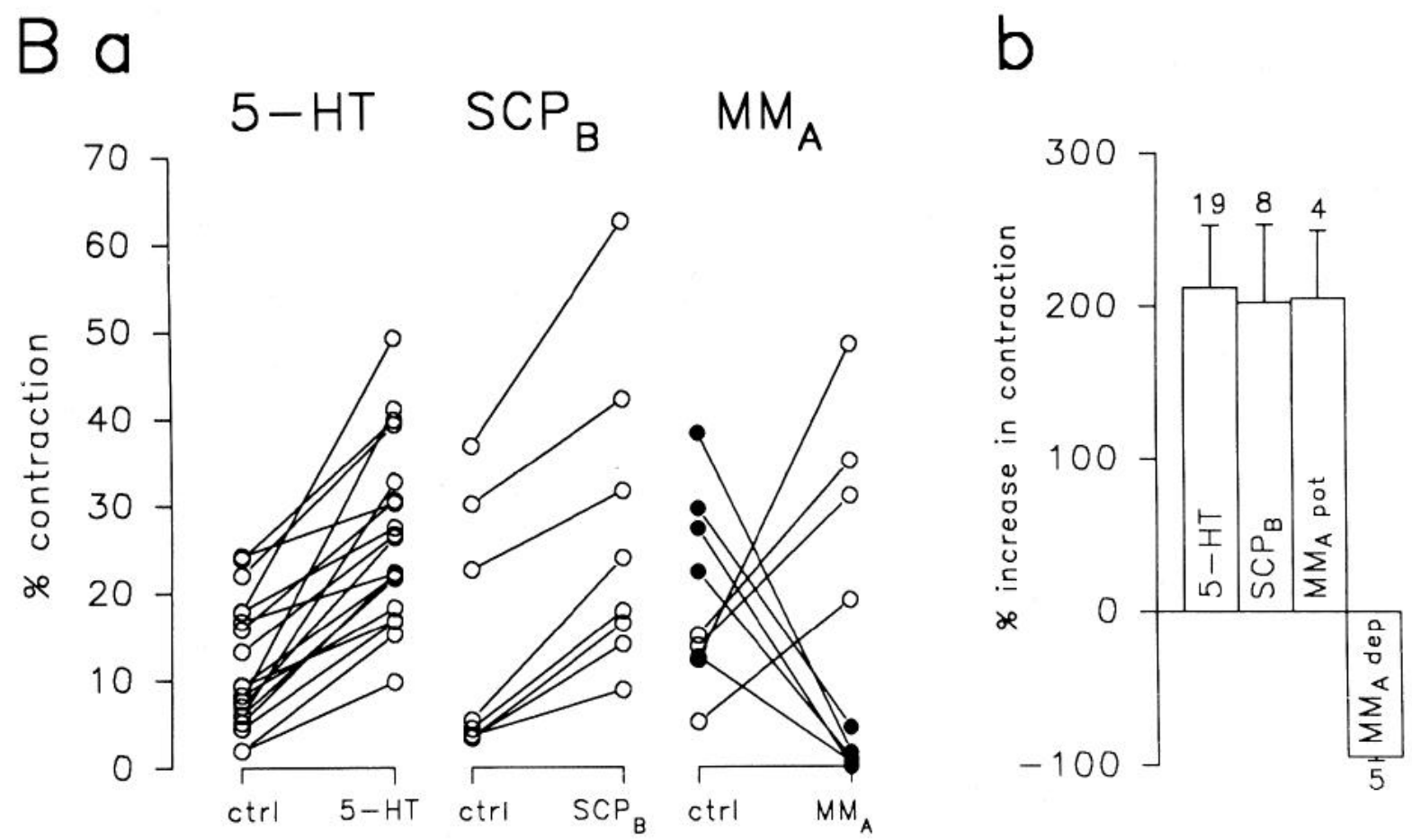

Figure 1. The postsynaptic modulators potentiate and depress contractions of single ARC muscle fibers. $A$, A fiber, initially about $650 \mu \mathrm{m}$ long, held with a suction pipette in a fast-flowing stream of normal ASW (flowing from top to bottom of the frame) while brief puffs of $10 \mu \mathrm{M}$ ACh were delivered at regular intervals from a second pipette (for further details, see Materials and Methods). In this experiment fast green dye was added to the puffed solution to visualize the trajectory of the puffed stream (in the second and fourth frames). The photographs were taken just before and at the peak of an ACh-induced contraction, under control conditions and following addition of $10 \mu \mathrm{M}$ 5-HT to the ASW flowing past the fiber. From pairs of observations or measurements of photographs like these, we calculated the percentage contraction (decrease in the length of the fiber expressed as percentage of the length just before) induced by the ACh puff under control conditions (here about $28 \%$ ) and following application of 5-HT (here $48 \%$ ) or another modulator. $B a$, Results, measured and calculated as just described, of a series of experiments like that in $A$. Each linked pair represents the percentage contraction of one fiber under control conditions and following application of $10 \mu \mathrm{M} 5-\mathrm{HT}, \mathrm{SCP}_{\mathrm{B}}$, or $\mathrm{MM}_{\mathrm{A}}$. In the case of $\mathrm{MM}_{\mathrm{A}}$, the plot shows the results obtained with one batch of fibers whose contractions were strongly potentiated by $\mathrm{MM}_{\mathrm{A}}(\mathrm{O})$, and another whose contractions were strongly depressed ( $)$ see text). $B b$, Summary of the results in $B a$. The modulated percentage contraction of each fiber was expressed as a percentage of its control percent contraction, and the means \pm SEMs of all of these values are plotted. The fibers whose contractions were potentiated by $\mathrm{MM}_{\mathrm{A}}$ and those whose contractions were depressed are represented separately. 

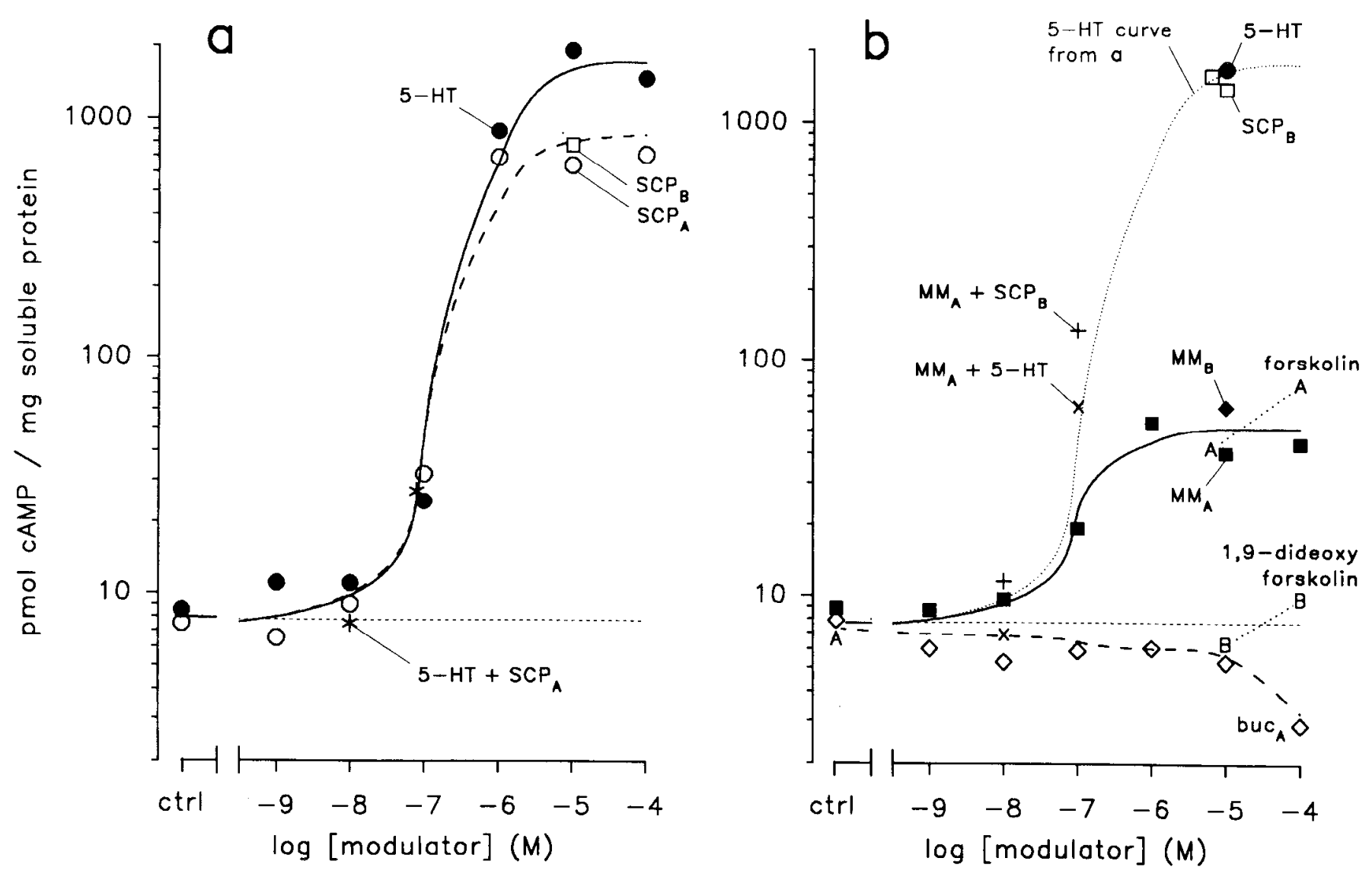

Figure 2. The postsynaptic modulators elevate $\mathrm{c} \Lambda \mathrm{MP}$ in dissociated ARC musclc fibcrs. The two pancls show the results of two separate cAMP assays carried out at different times on different pools of dissociated fibers (see Materials and Methods). In the assay in $a$, the fibers were treated with the modulators (or control normal ASW only) in all cases for $5 \mathrm{~min}$. In the assay in $b$, the treatments with 5 -HT alone, buccalin A $_{\mathrm{A}}$, forskolin and 1,9-dideox yforskolin were for $5 \mathrm{~min}$, the treatment with $\mathrm{SCP}_{\mathrm{B}}$ alone was for 2 or 5 min (yielding the two essentially identical "SCP," points), and the treatments with $\mathrm{MM}_{\mathrm{A}}$ alone, $\mathrm{MM}_{\mathrm{A}}$ plus $5-\mathrm{HT}, \mathrm{MM}_{\mathrm{A}}$ plus $\mathrm{SCP}_{\mathrm{B}}$, and $\mathrm{MM}_{\mathrm{B}}$ were for 2 min. The control treatments were with normal ASW only for 2 or $5 \mathrm{~min}$, and with normal ASW containing $0.3 \% \mathrm{v} / \mathrm{v}$ DMSO for $5 \mathrm{~min}$ (control point $A$ ). The treatments involving the MMs were made short because in the intact AKC muscle the MM-induced elevation in cAMP has been found to peak about 2 min after the beginning of the MM application and to decline fast thereafter, unlike the effects of 5-HT and $\mathrm{SCP}_{\mathrm{B}}$, whose desensitization is much slower (Hooper et al., 1992; S. L. Hooper and W. C. Probst, personal communication; in the assays shown here, too, cAMP clearly remains high at the end of a 5 min exposure to 5-HT or $\mathrm{SCP}_{\mathrm{B}}$ ). In both $a$ and $b$, in the cases when the treatment was a combination of two different modulators, both were applied at the same concentration, either $10^{-8}$ or $10^{-7} \mathrm{M}$. Some of the symbols have been displaced horizontally to avoid overlap.

of measuring fiber length with good time resolution are currently being developed for this purpose.

Exposure to $10 \mu \mathrm{M} 5-\mathrm{HT}$ or $\mathrm{SCP}_{\mathrm{B}}$ invariably greatly potentiated the amplitude of the contractions, $5-\mathrm{HT}$ by $212 \pm 40 \%$ (mean $\pm \mathrm{SEM}, n=19)$ and $\mathrm{SCP}_{\mathrm{B}}$ by $202 \pm 51 \%(n=8$; Fig. $1 A, B)$. The potentiation was marked already at the very next contraction after the beginning of the 5-HT or $\mathrm{SCP}_{\mathrm{B}}$ application (i.e., certainly within $60 \mathrm{sec}$, the standard interval between the contractions, but our impression was that considerable potentiation was in fact already present after only a few seconds' exposure to the 5-HT or $\mathrm{SCP}_{\mathrm{B}}$ ), and continued to develop still more over the subsequent two or three contractions. Even after 15 min in the continuous presence of $5-\mathrm{HT}$ or $\mathrm{SCP}_{\mathrm{B}}$, the potentiation showed no obvious desensitization. In preliminary experiments, $\mathrm{ACh}$-independent contractions elicited by depolarizing the fiber by current injection or puffs of high- $\mathrm{K}^{+}$solution were similarly potentiated (Březina and Weiss, 1993; see Discussion). These results confirmed and extended the work of Ram et al. (1991), who have previously reported that contractions of dissociated $\mathrm{ARC}$ muscle fibers elicited by $\mathrm{ACh}$ or high- $\mathrm{K}^{+}$solution are potentiated by 5 -HT.
The effect of $\mathrm{MM}_{\mathrm{A}}$ was more complex. In the whole ARC muscle, $M_{\mathrm{A}}$ can either potentiate or depress contractions (Cropper et al., 1991), most plausibly because it simultaneously activates competing potentiating and depressing mechanisms. The dissociated fibers behaved very similarly. Responses of different fibers to $\mathrm{MM}_{\mathrm{A}}$ ranged from strong potentiation through relatively weak potentiation or depression to strong depression. In this initial series of experiments, we wished simply to document that both the potentiation and depression were functional in the dissociated fibers. In Figure $1 B$, we therefore present results from two batches of fibers with extreme responses. In one batch, presumably fibers in which the potentiating mechanism(s) was by far dominant, $10 \mu \mathrm{M} \mathrm{MM}_{\mathrm{A}}$ potentiated contractions by $205 \pm 44 \%(n=4)$, as much as 5 -HT or $\mathrm{SCP}_{\mathrm{B}}$. In the other batch, presumably fibers in which the depressing mechanism(s) predominated, $10 \mu \mathrm{M} \mathrm{MM}_{\mathrm{A}}$ depressed contractions by $94 \pm 3 \%(n=5)$, that is, almost completely arrested them. The time course of the potentiation by $\mathrm{MM}_{\mathrm{A}}$ was similar to that seen with $5-\mathrm{HT}$ or $\mathrm{SCP}_{\mathrm{B}}$. The depression, however, was most profound at the first or second contraction in $\mathrm{MM}_{\mathrm{A}}$ and then desensitized; the contractions gradually grew larger again even in 
the continued presence of $\mathrm{MM}_{\mathrm{A}}$, though never (within $15 \mathrm{~min}$ ) as far as their pre- $\mathrm{MM}_{\mathrm{A}}$ amplitude. Elsewhere, in the context of a more extensive description of the contractions of the dissociated fibers and their modulation, we shall examine the more common - and probably more physiological-case of the fibers whose contractions $\mathrm{MM}_{\mathrm{A}}$ potentiates or depresses to a less extreme degree, most likely fibers in which the strengths of the potentiating and depressing mechanisms are more balanced (see Discussion of the following article, Březina et al., 1994d). In the meantime, all indications were that the modulation of contractions by the MMs as well as the SCPs and 5-HT, and thus presumably the mediating cellular mechanisms, remained normally functional in the dissociated ARC muscle fibers.

\section{Modulation of $C A M P$ concentration in the dissociated ARC muscle fibers}

It is likely that the postsynaptic modulators all act on the ARC muscle at least in part via cAMP (see Discussion). The SCPs and 5-HT greatly elevate cAMP in the whole muscle (Weiss et al., 1979; Lloyd et al., 1984; Whim and Lloyd, 1989), and recently the MMs have been found to do so too, though to a lesser extent (Hooper et al., 1992). We were able to reproduce all of these effects, including for the most part even their magnitude and concentration dependence, in the dissociated fibers.

Thus, beginning at about $10 \mathrm{nM}$ and saturating above $1 \mu \mathrm{M}$, both the SCPs and 5-HT elevated cAMP several hundred fold; the effects of $\mathrm{SCP}_{\mathrm{A}}$ and $\mathrm{SCP}_{\mathrm{B}}$ appeared indistinguishable (Fig. $2 a, b)$. Over about the same range of concentrations, both $\mathrm{MM}_{\mathrm{A}}$ and $\mathrm{MM}_{\mathrm{B}}$ likewise elevated cAMP, but maximally only about sevenfold (Fig. $2 b$ ). Although we did not investigate the question exhaustively, we saw no obvious indication of any synergism between the effects of 5-HT and SCP (Fig. 2a) or MM and 5-HT

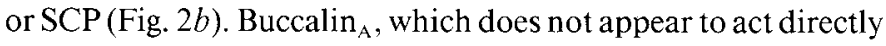
on the ARC muscle (see introductory remarks) and does not affect cAMP in the whole muscle (Whim and Lloyd, 1989), did not affect, or perhaps even somewhat depressed, cAMP in the dissociated fibers (Fig. 2b). Finally, the adenylyl-cyclase activator forskolin (Laurenza et al., 1989), which moderately elevates cAMP in the whole muscle and potentiates its contractions (Ram et al., 1984a; Hooper et al., 1991), elevated cAMP in the dissociated fibers about as much as the MMs, about sevenfold at $10 \mu \mathrm{M}$ and 10 -fold at $100 \mu \mathrm{M}$ (Fig. 2b). In contrast, its "inactive" analog 1,9-dideoxyforskolin (Laurenza et al., 1989) had little or no effect even at $100 \mu \mathrm{M}$ (Fig. $2 b$ ). (However, the analog was inactive only as far as stimulation of adenylyl cyclase was concerned: as we report below and in the following article, it had, as in other preparations, what must be presumed to be cAMP-independent effects.)

\section{Modulation of Ca current}

In the third of our earlier articles, we reported that the ARC muscle fibers possess a prominent, homogeneous $\mathrm{Ca}$ current whose characteristics - relatively depolarized voltage ranges of activation and steady-state inactivation, larger amplitude when carried by $\mathrm{Ba}^{2+}$ than $\mathrm{Ca}^{2+}$, slow current-dependent inactivation, and sensitivity to dihydropyridine Ca-channel antagonistswould in the vertebrate classification place it into the "L" class (Březina et al., 1994c). Modulation of this current is the subject of the rest of this article.

Unless complete $I-V$ relations were to be obtained, we studied the current with standard voltage steps from -90 to $0 \mathrm{mV}$ (e.g., Fig. 3Aa), which elicited currents of near-maximal amplitude (Březina et al., 1994c; see Figs. 4, 10A). We preferred to study the current when carried by $\mathrm{Ba}^{2+}$ rather than $\mathrm{Ca}^{2+}$, as Ba currents were larger, less subject to current-dependent inactivation, and less at risk of contamination by residual unblocked outward currents (Březina et al., 1994c). However, as will be seen, we found the modulation of $\mathrm{Ca}$ and $\mathrm{Ba}$ currents to be essentially identical. To isolate the $\mathrm{Ca}$ or $\mathrm{Ba}$ current, all experiments were carried out in $\mathrm{Na}^{+}$-free solution containing high concentrations of K-current blockers, $460 \mathrm{~mm}$ tetraethylammonium (TEA) and (usually) $10 \mathrm{~mm}$ 4-aminopyridine (4-AP). Further, we routinely subtracted from the $\mathrm{Ca}$ - or Ba-current records the capacitive transients, leakage current, and any other residual current that remained when all of the extracellular $\mathrm{Ca}^{2+}$ or $\mathrm{Ba}^{2+}$ was replaced with $\mathrm{Co}^{2+}$ at the end of the experiment (e.g., Figs. 3B, 7A). For further details and discussion of these techniques, see Materials and Methods and Březina et al. (1994c).

The Ca or Ba current was substantially enhanced by all of the postsynaptic modulators - 5-HT (e.g., Figs. $3 B, 6 A ; 48$ fibers), $\mathrm{SCP}_{\mathrm{A}}$ (Fig. $7 A, 3$ fibers) and $\mathrm{SCP}_{\mathrm{B}}$ (Fig. $4 B, 36$ fibers), and $\mathrm{MM}_{\mathrm{A}}$ (Fig. $3 A a, 33$ fibers) and $\mathrm{MM}_{\mathrm{B}}$ (Fig. $7 B C, 5$ fibers). In most of these experiments we studied the Ba current, but in two of the fibers tested with 5-HT, five with $\mathbf{S C P}_{\mathrm{B}}$, and two with $\mathbf{M M}_{\mathrm{A}}$, we observed that the Ca current was very similarly enhanced (e.g., Figs. $3 A b, 4 B$ ). The effects of the different modulators were essentially indistinguishable. We routinely applied the modulators at $1 \mu \mathbf{M}$, a near-maximal concentration (see below), at which each typically enhanced the Ca or Ba current by $50-100 \%$ (see Fig. 6). However, the enhancement was often larger particularly in fibers with relatively small basal Ca or Ba currents (e.g., Figs. $6 A, 7 B a, 9 A, C$ ), and smaller in fibers with large basal currents. Such variability, as most variability in the dissociated fibers, was generally much larger between batches of fibers dissociated from muscles from different animals than hetween fibers within the same batch. Within a batch, the basal currents were often quite uniform in amplitude, and were enhanced by a modulator to a similar extent. Moreover, the magnitudes of the effects of all of the different modulators appeared closely correlated. When, as occasionally happened, a batch of fibers responded poorly or not at all, it did so to all of the modulators.

Much of the enhancement of the Ca or Ba current developed within seconds after application of the modulator, at a rate indistinguishable from the speed of bath exchange (see Materials and Methods). However, many fibers exhibited a second, distinctly slower phase of the enhancement, so that the current did not stabilize at its fully enhanced amplitude sometimes for many minutes (e.g., Fig. $3 B$ ). The slow phase was most likely an intrinsic component of the enhancement, but it could also in part have reflected a gradual block by the enhanced amount of $\mathrm{Ba}^{2+}$ entering the fiber of residual outward currents partially masking the Ba current, such as was sometimes observed when stimulation was first started in $\mathrm{Ba}^{2+}$-containing solution at the beginning of an experiment (see Březina et al., 1994c). Even after $15 \mathrm{~min}$ in the continuous presence of the modulators, the enhancenleni showed no desensitization. Moreover, it was practically irreversible: it did not wash out even after $30 \mathrm{~min}$ (see Fig. $3 B$ ), even when a submaximal concentration of the modulator, for example, $100 \mathrm{~nm}$ (see below), had been applied (three to five fibers were tested with each of 5-HT, $\mathrm{SCP}_{\mathrm{B}}$ and $\mathrm{MM}_{\mathrm{A}}$ ).

Several observations indicated that the modulator-induced increase in inward current represented genuine enhancement of 

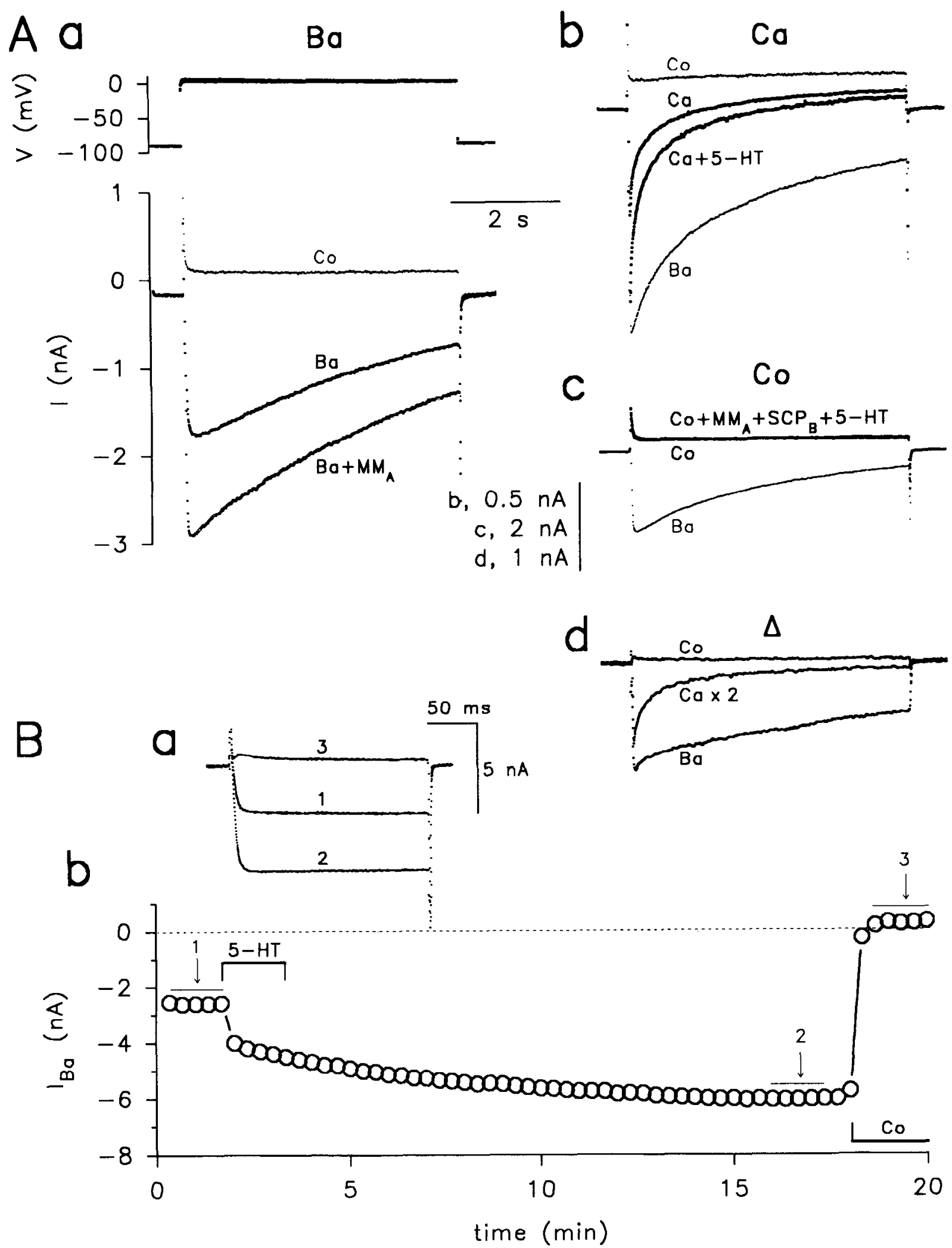

Figure 3. The postsynaptic modulators enhance Ca-channel current carried by $\mathrm{Ca}^{2+}$ or $\mathrm{Ba}^{2+} . A$, Currents were elicited in three different fibers by long ( $5 \mathrm{sec}$ ) voltage steps $(A a, t o p)$ from -90 to $0 \mathrm{mV}$ in $\mathrm{Ba} / \mathrm{TEA}(A a)$ or $\mathrm{Ba} / \mathrm{TEA} / 4-\mathrm{AP}(A b, A c)$ ASW $(B a$ traces $)$, Ca/TEA/4-AP ASW $(C a$ traces), and Co/TEA $(A a)$ or Co/TEA/4-AP $(A b, A c)$ ASW (Co traces). All currents are shown unsubtracted. In $A a$, the Ba current was enhanced by $1 \mu \mathrm{M}$ $\mathrm{MM}_{\mathrm{A}}$; in $A b$, the Ca current was enhanced by $1 \mu \mathrm{M} 5-\mathrm{HT}$; in $A c$, however, even combined application of $10 \mu \mathrm{M}$ of each of $\mathrm{MM}_{\mathrm{A}}, \mathrm{SCP}_{\mathrm{B}}$, and 5-HT had no effect on the residual current remaining after replacement of all of the extracellular $\mathrm{Ba}^{2+}$ or $\mathrm{Ca}^{2+}$ with $\mathrm{Co}^{2+} . \mathrm{Ad}^{2}$ shows the net modulatorsensitive difference currents obtained by subtracting the control from the enhanced current in each of $A a-A c$ (the "Ca" difference current has been scaled up twofold for clarity). $B$, Time course of the enhancement. Currents were elicited by short ( $200 \mathrm{msec}$ ) voltage steps from -90 to $0 \mathrm{mV}$ in $\mathrm{Ba} / \mathrm{TEA} \mathrm{ASW}$, and at the end of the experiment in Co/IEA ASW. $B b$ shows a running plot of the (unsubtracted) peak Ba current; $B a$, the (unsubtracted) currents (each an average of several raw traces) recorded at the times indicated in $B b .5-\mathrm{HT}$ at $1 \mu \mathrm{M}$ was applied briefly, and then washed out. Note the fast and slow phases and the long persistence of the enhancement (see text). 

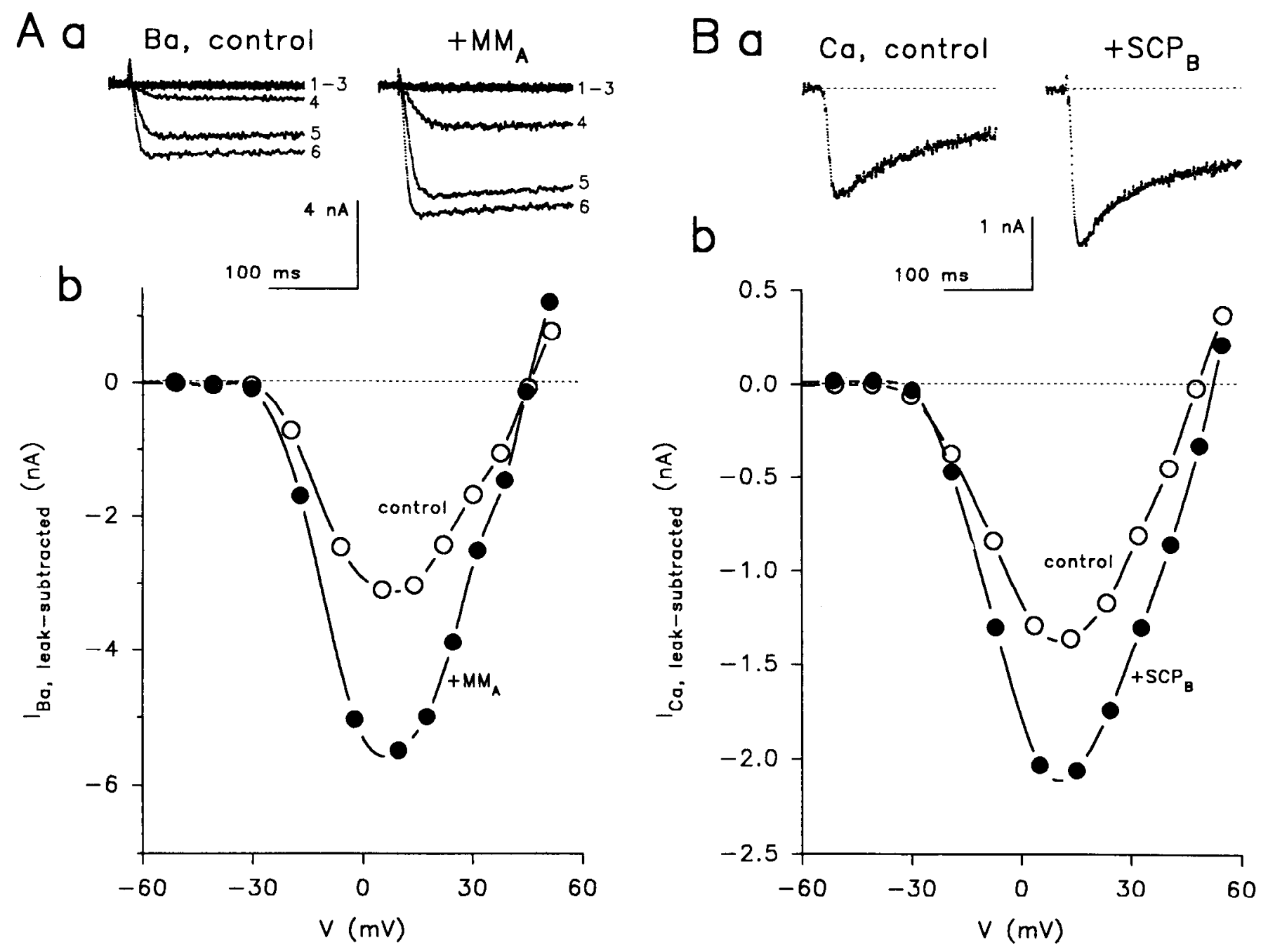

Figure 4. I-V relations of basal and enhanced $\mathrm{Ca}$ and Ba currents. Currents were elicited by short (200 msec) voltage steps from $-90 \mathrm{mV}$ to a range of test potentials to obtain complete $I-V$ relations, in Ba/TEA/4-AP ASW $(A)$ or Ca/TEA ASW $(B)$. $A b$ shows $I-V$ relations of the peak or most inward $\mathrm{Co}^{2}$-leak subtracted Ba current before and after application of $1 \mu \mathrm{M} \mathrm{MM}_{\mathrm{A}} ; A a$, the (subtracted) currents elicited in each case by the steps to the six most negative test potentials (traces $1-6$, respectively) in $A b . B b$ similarly shows $I-V$ relations of (subtracted) $C a$ current before and after application of $1 \mu \mathrm{M} \mathrm{SCP}$, and $B a$ the (subtracted) currents elicited in each case by the step to the test potential closest to $0 \mathrm{mV}$.

the $\mathrm{Ca}$ or $\mathrm{Ba}$ current, rather than, for instance, suppression of a contaminating outward current.

(1) The high concentrations of TEA and 4-AP present in these experiments blocked the outward currents normally seen in the fibers very effectively (Březina et al., 1994b); probably the largest current that remained summed with the true inward $\mathrm{Ca}$ or $\mathrm{Ba}$ current was the time-independent leakage current revealed when the $\mathrm{Ca}$ or $\mathrm{Ba}$ current was then blocked with $\mathrm{Co}^{2+}$ (e.g., Fig. 3AC). This current, as well as any unblocked remnants of the other outward currents that might still have contaminated the $\mathrm{Ca}$ or Ba current (see Brezina et al., 1994c, and below), appeared in most fibers to be much too small to account for the large absolute amplitude of inward current induced by the modulators.

(2) Indeed, direct tests of the leakage current remaining in $\mathrm{CO}^{2+}$-containing solution showed that it was totally unaffected by even $10 \mu \mathrm{M} 5-\mathrm{HT}, \mathrm{SCP}_{\mathrm{B}}$, and $\mathrm{MM}_{\mathrm{A}}$ (Fig. $3 \mathrm{Ac}$; two or three fibers were tested with each modulator either alone or in combination). Thus, when the Ca or Ba current was blocked, so was the effect of the modulators. [This experiment further showed that the second effect of the modulators described in the following article, activation of a large $\mathrm{K}$ current that in normal
ASW was clearly evident during voltage steps like those used here, was here completely absent. Since this K current was unaffected by $\mathrm{Co}^{2+}$ but was well blocked by high TEA and still better by even low concentrations of 4-AP (Březina et al., 1994d), it was presumably blocked not just in $\mathrm{Co}^{2+}$-containing solution but throughout the experiments described in this article, and did not interfere with our examination of the effects of the modulators on the $\mathrm{Ca}$ or $\mathrm{Ba}$ current.]

(3) Finally, the modulator-induced increase in inward current always remained proportional (though, as already noted, the exact proportion differed from fiber to fiber) to the amplitude of the basal, unmodulated $\mathrm{Ca}$ or $\mathrm{Ba}$ current even as this amplitude varied considerably as the current activated and then inactivated during the voltage step, was blocked in a time-dependent manner by drugs, or was elicited by steps to different voltages. Thus, most strikingly when the slow inactivation of the Ba current was compared with the faster inactivation of the Ca current (e.g., Fig. $3 A b$; compare also Fig. $4, A a$ vs $B a$ ), or when the decay of the current was speeded still more and its amplitude progressively reduced by increasing concentrations of nifedipine (see Fig. $11 \mathrm{~B}$ and below), the shape of the enhanced 


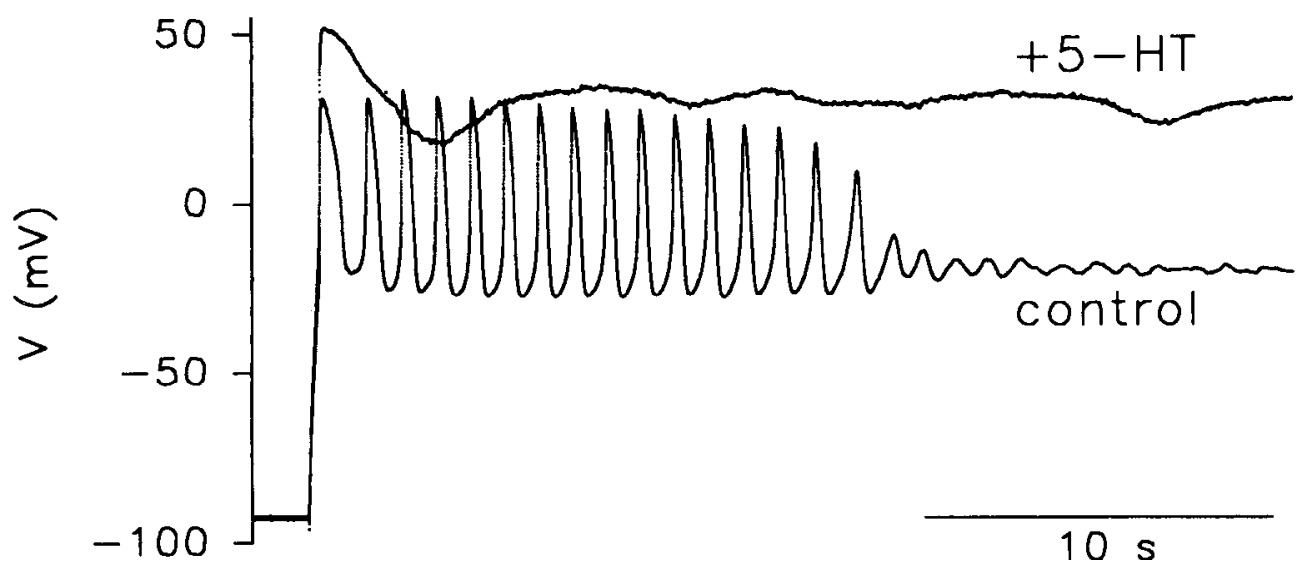

Figure 5. Enhancement of $\mathrm{Ba} / \mathrm{TEA}$ spikes in unclamped fibers. Here, a fiber bathed in Ba/TEA ASW was first voltage clamped at $-90 \mathrm{mV}$, and then released from clamp, before and after application of $1 \mu \mathrm{M} 5$-HT current, and thus of the net modulator-induced difference current (Fig. $3 A d$ ), always closely resembled that of the basal current. The modulators thus acted, to a first approximation, by simply scaling up the basal current by a constant proportion without having much effect on its kinetics. (The only systematic effect, a small increase in the rate of inactivation of the enhanced current, will be considered later.) Similarly, the modulators simply scaled up by a constant proportion the $I-V$ relation of the basal Ca (Fig. $4 B$ ) or Ba (Fig. $4 A$ ) current (two or three fibers were tested with each of $5-\mathrm{HT}, \mathrm{SCP}_{\mathrm{B}}$, and $\mathrm{MM}_{\mathrm{A}}$ ). They had no effect at voltages below the activation threshold of the basal current. Furthermore, the outward basal current above its reversal potential at about +40 or $+50 \mathrm{mV}$, which probably flowed at least in part through the Ca channels themselves (Březina et al., 1994c), was enhanced by the modulators likewise in the outward direction in some experiments (e.g., Fig. $4 A b$ ). These correlations added to our confidence that the modulators indeed acted on the true $\mathrm{Ca}$ or $\mathrm{Ba}$ current.

Earlier, we reported that while ARC muscle fibers do not spike when bathed in normal ASW, they begin to do so as their K currents become blocked upon superfusion of Ba/TEA ASW (Březina et al., 1994b). Eventually, many fibers remain permanently depolarized between +30 and $+50 \mathrm{mV}$ by the now essentially unopposed Ba current. Sometimes, however, spontaneous spiking continues, most likely reflecting cyclical activation, inactivation, and repriming of the Ba current in those fibers in which it is small enough, or the residual $\mathrm{K}$ currents are large enough, for the inward and outward currents to be roughly balanced (Březina et al., 1994b). Consistent with this interpretation and action of the modulators on the Ba current, the spikes wcre cnhanced in amplitudc and duration and eventually converted into the permanent depolarization by application of 1 $\mu \mathrm{M}$ 5-HT (Fig. 5, three fibers).

Figure $6 B$ shows dose-response relations for the enhancement of the Ba current by 5-HT (five fibers; nine others yielded similar but only partial data), $\mathrm{SCP}_{\mathrm{B}}$ (three fibers), and $\mathrm{MM}_{\mathrm{A}}$ (three fibers). The three dose-response relations are very similar: each modulator began to enhance the Ba current at about $1 \mathrm{~nm}$, and enhanced it maximally above $1 \mu \mathrm{M}$. As already mentioned, the magnitude of the maximal enhancement by each of the modulators was also similar, typically 50-100\% of the amplitude of the basal current. Furthermore, the modulators all acted in a mutually occlusive fashion: once the Ba current had been maximally enhanced by one modulator (usually applied at $1 \mu \mathrm{M}$ ), none of the others had any further effect (Fig. $7 A, B ; 17$ fibers were tested with various combinations of $5-\mathrm{HT}, \mathrm{SCP}_{\mathrm{A}}, \mathrm{SCP}_{\mathrm{B}}$,
$\mathrm{MM}_{\mathrm{A}}$, and $\mathrm{MM}_{\mathrm{B}}$ ). These findings confirmed that all of the modulators acted on the same $\mathrm{Ca}$ or Ba current. However, we found no evidence of synergism or any other interaction between the effects of the different modulators: submaximal enhancement of the Ba current by two different modulators appeared simply additive (Fig. $7 C$; four fibers were tested with $\mathrm{MM}_{\mathrm{A}}$ plus $5-\mathrm{HT}$ or $\mathrm{SCP}_{\mathrm{B}}$ ).

In contrast to the postsynaptic modulators, the presynaptic modulator buccalin $_{\mathrm{A}}$ had no noticeable effect on the basal $\mathrm{Ca}$ or Ba current at any concentration between $10 \mathrm{~nm}$ (where its presynaptic effects already begin to be noticeable: Cropper et al., 1988) and $1 \mu \mathrm{M}$ (Fig. 8a, 11 fibers), and its presence did not prevent or apparently modify in any way enhancement of the current by further application of 5-HT, $\mathrm{SCP}_{\mathrm{B}}$ or $\mathrm{MM}_{\mathrm{A}}$ (Fig. $8 a$,

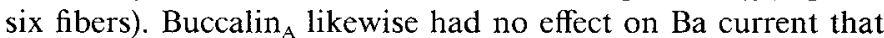
had already been enhanced by 5 -HT (Fig. $8 b$ ), $\mathrm{SCP}_{\mathrm{B}}$, or $\mathrm{MM}_{\mathrm{A}}$ (Fig. $8 c$, five fibers)

\section{Elevation of CAMP mimics and occludes the modulator- induced enhancement}

As we have already described, the postsynaptic modulators elevate cAMP in the ARC muscle, and the sum of available evidence makes it likely that the CAMP mediates at least some of their effects (see Discussion). To determine whether the elevation in CAMP might mediate the enhancement of the $\mathrm{Ca}$ or $\mathrm{Ba}$ current, we elevated cAMP in the dissociated fibers in the absence of the modulators with the adenylyl-cyclase activator forskolin or by direct application of the membrane-permeable cAMP analog 8-chlorophenylthio-cAMP (CPT-cAMP) together with the phosphodiesterase inhibitor Ro 20-1724. (Forskolin, CPTcAMP, and Ro 20-1724 have all been found effective in the whole ARC muscle; see Discussion.)

Both forskolin (Fig. 9A, eight fibers) and CPT-cAMP plus Ro 20-1724 (Fig. $9 B, 16$ fibers) indeed perfectly mimicked the modulator-induced enhancement of the $\mathrm{Ca}$ or $\mathrm{Ba}$ current. Maximal enhancement by these agents, just as by the modulators, was of the order of $100 \%$. Furthermore, the maximal effects of the cAMP-elevating agents and the modulators mutually occluded each other (Fig. 9C, 11 fibers). The single forskolin concentration tested, $50 \mu \mathrm{M}$ (which, as we showed in Fig. $2 b$, elevated cAMP in the fibers about as much as $\mathrm{MM}_{\mathrm{A}}$ ), was apparently already maximal, as its effect fully occluded those of the modulators (e.g., Fig. 9Cb, three fibers). However, $100 \mu \mathrm{M}$ CPTcAMP (plus $100 \mu \mathrm{M}$ Ro 20-1724) appeared submaximal, as the modulators still had clear additional effects (Fig. $9 C_{C} c$, three fibers). It was necessary to raise the CPT-cAMP concentration 

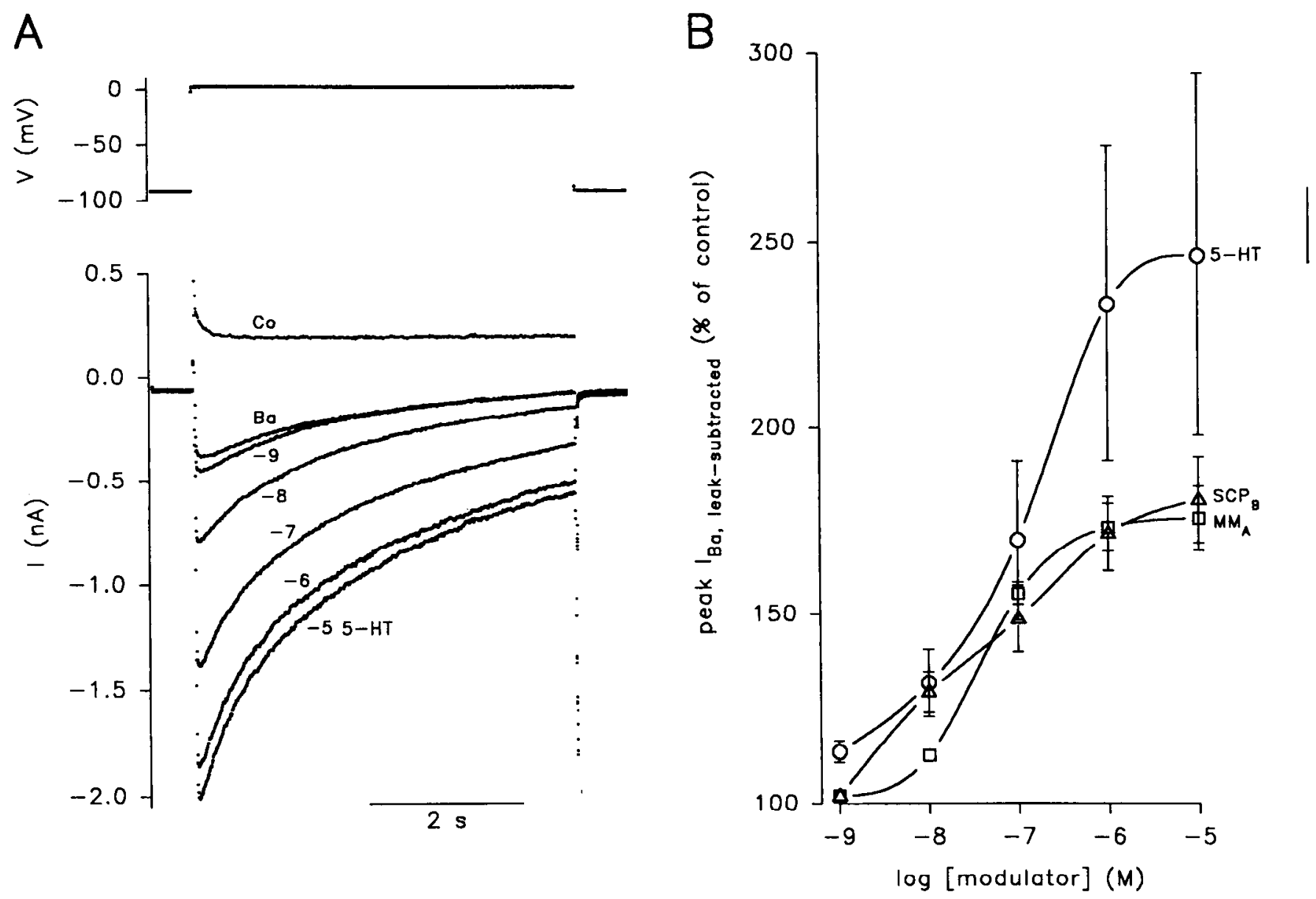

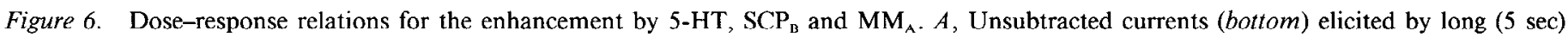
voltage steps from -90 to $0 \mathrm{mV}(t o p)$, first in control Ba/TEA/4-AP ASW, and then following application of successively higher concentrations, from $1 \mathrm{~nm}$ to $10 \mu \mathrm{M}\left(10^{-9}\right.$ to $\left.10^{-5} \mathrm{M}\right)$, of 5-HT, and finally in Co/TEA/4-AP ASW. No wash appeared necessary between the successive 5-HT applications since the enhancement of $\mathrm{Ca}$-channel current did not desensitize; washing would in any case have been difficult due to the long persistence of the enhancement (see text and Fig. $3 B$ ). $B$, Summary dose-response plots (means \pm SEMs) of measurements from $A$ and four other fibers of the percentage increase in peak $\mathrm{CO}^{2+}$-leak subtracted $\mathrm{Ba}$ current caused by different 5-HT concentrations, and from three similar experiments with $\mathrm{SCP}_{\mathrm{B}}$ and three with $\mathrm{MM}_{\mathrm{A}}$. The apparently larger enhancement caused by $5-\mathrm{HT}$ than by $\mathrm{SCP}_{\mathrm{B}}$ or $\mathbf{M M}_{\mathrm{A}}$ is due to inclusion in the averaged 5-HT data of measurements from two fibers (the fiber in $A$ was one) that gave unusually large responses (note the large error bars in $B$ ) perhaps because their starting basal currents were unusually small; similarly large responses were on occasion seen also with $\mathrm{SCP}_{\mathrm{B}}$ and $\mathrm{MM}_{\mathrm{A}}(\mathrm{see}$ text).

to $1 \mathrm{~mm}$ before its effect fully occluded those of the modulators (Fig. $9 \mathrm{Cd}$, four fibers). Finally, in contrast to forskolin, its "inaclive" analog 1,9-dideoxyforskolin (which, as we showed in Fig. $2 b$, indeed failed to elevate cAMP in the dissociated fibers even at $100 \mu \mathrm{M})$ as expected did not enhance the $\mathrm{Ca}$ or $\mathrm{Ba}$ current. Instead, unexpectedly, it reversibly suppressed it, at $100 \mu \mathrm{M}$ by as much as $50 \%$ (five fibers). This effect was probably not mediated by a decrease in cAMP (for which we in any case found no evidence in Fig. $2 b$ ), as the 1,9-dideoxyforskolin effectively suppressed even Ba current maximally enhanced by, and in the continued presence of, $1 \mathrm{~mm}$ CPT-cAMP plus 100 $\mu \mathrm{M}$ Ro 20-1724 (two fibers). Therefore, this must be presumed to be another of the many cAMP-independent actions of the forskolins that have now been recognized in a variety of preparations (reviewed by Laurenza et al., 1989).

\section{Further comparison of the basal and enhanced current: one current or two?}

We have already noted that the enhanced $\mathrm{Ca}$ or $\mathrm{Ba}$ current activated and inactivated with a similar time course, and had the same $I-V$ relation, as the basal, unmodulated current, consistent with the idea that the modulators and elevation in CAMP simply enhanced the preexisting current, rather than inducing a new current through a population of $\mathrm{Ca}$ channels with different characteristics (but see Discussion). To obtain further relevant data, we compared the basal and enhanced Ba current with respect to two further distinctive characteristics of " $L$ "-type current, its relatively depolarized voltage range of steady-state inactivation and its sensitivity to dihydropyridine Ca-channel antagonists such as nifedipine (see Brezina et al., 1994c). These further tests were all the more important as we noticed that the rate of inactivation of the enhanced $\mathrm{Ba}$ current ( $\mathrm{Ca}$ currents were not explicitly examined in this regard) was often not exactly identical to that of the basal current, but was systematically faster. In the most striking examples (e.g., Fig. $9 B, C a, C b$ ), particularly the peak of the enhanced current was much sharper than that of the basal current. This may have been in part an artifact, as it was most often observed in fibers with significant residual outward-current contamination of the Ba current, judging by such signs as its small size, atypically slow activation, 


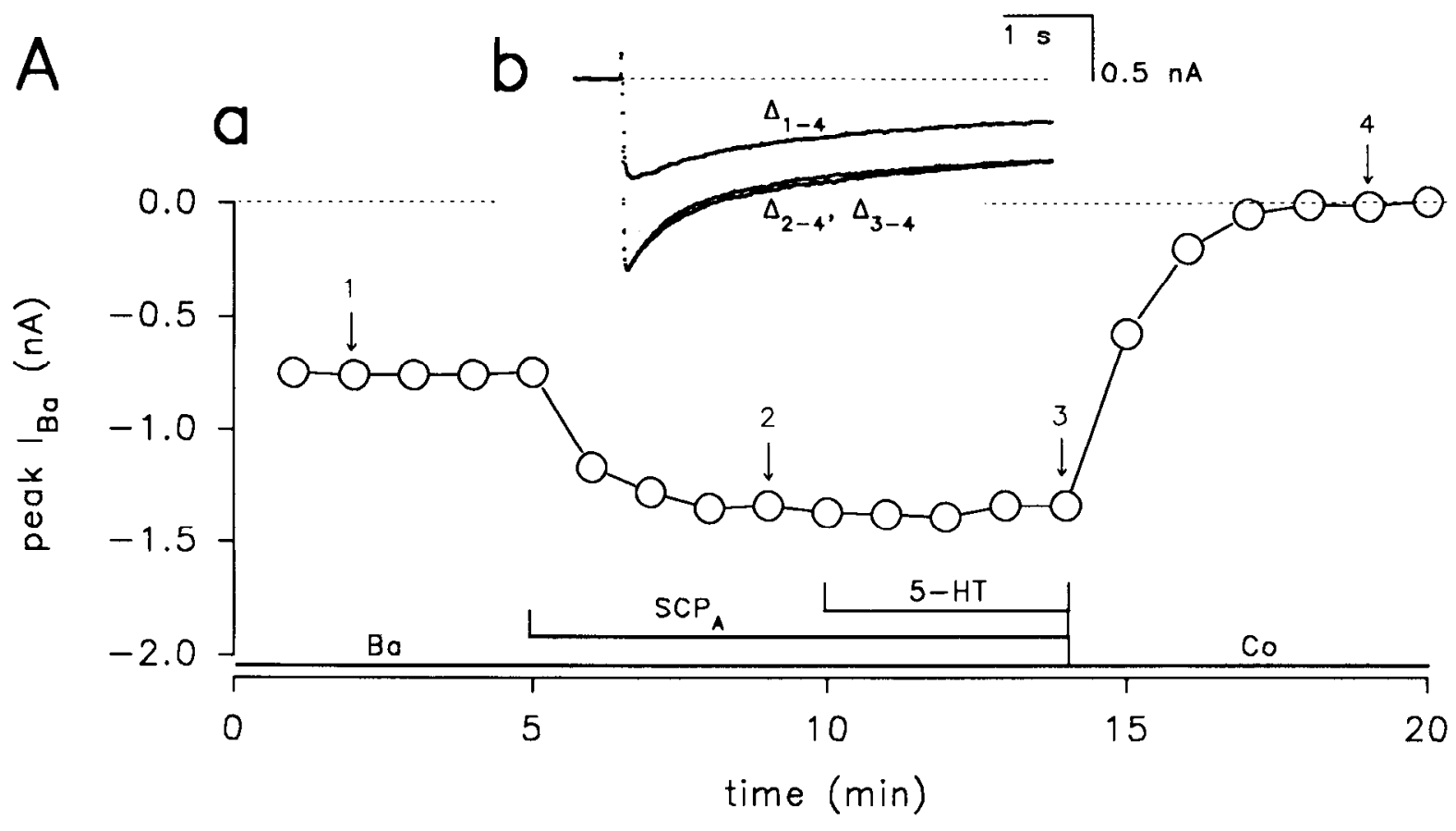

B a

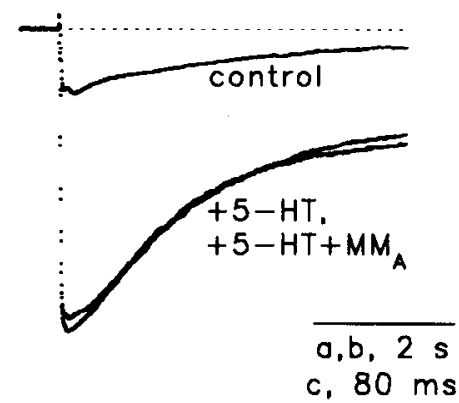

$\mathrm{C}$ a

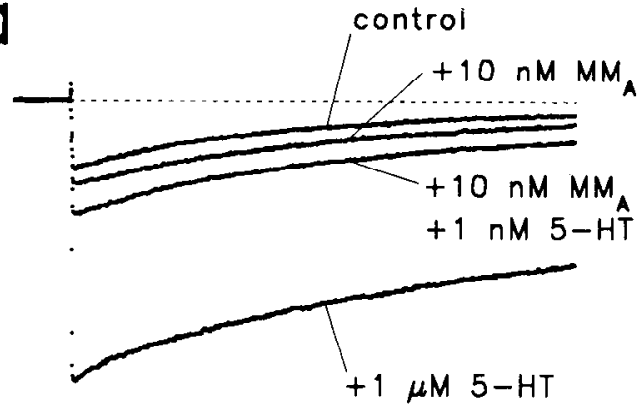

b

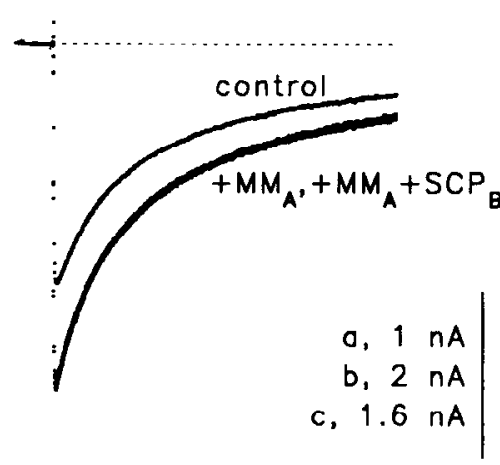

c

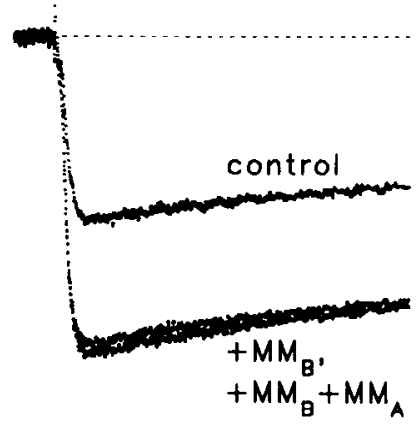

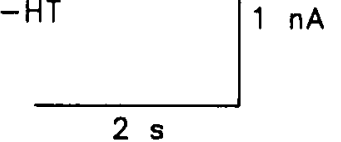

b

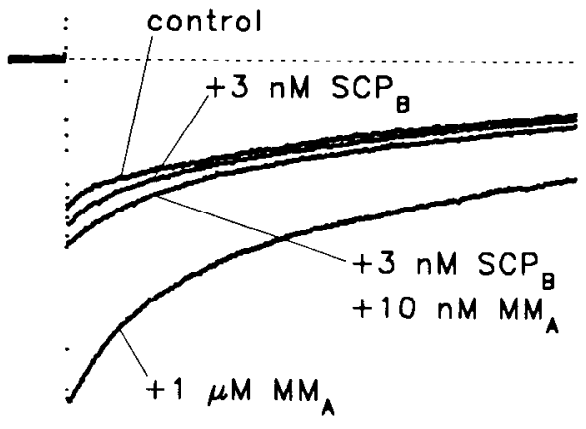

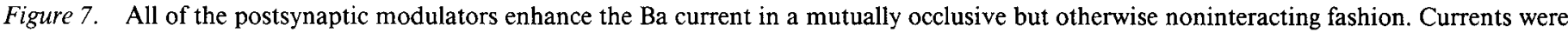

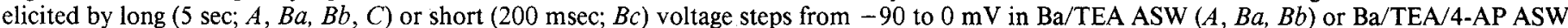

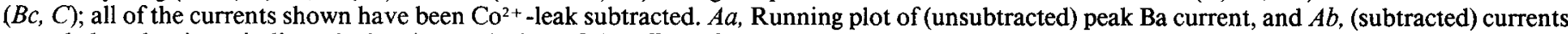

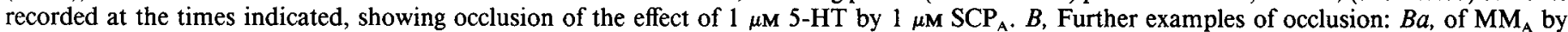

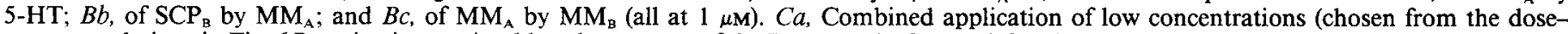

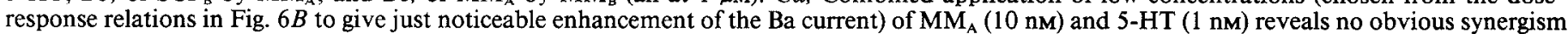

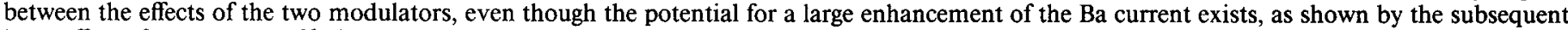
large effect of $1 \mu \mathrm{M} 5-\mathrm{HT}$. $C b$, Same as $C a$, with $3 \mathrm{nM} \mathrm{SCP}$ together with $10 \mathrm{nM}_{\mathrm{B}} \mathbf{M M}_{\mathrm{A}}$, and then $1 \mu \mathrm{M} \mathrm{MM}_{\mathrm{A}}$. 
a

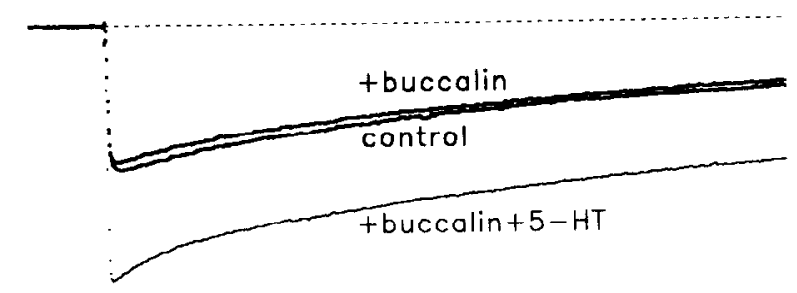

b

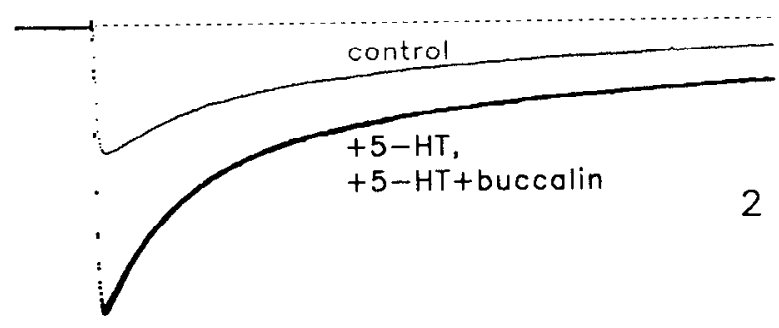

$2 n A$

$2 s$

C

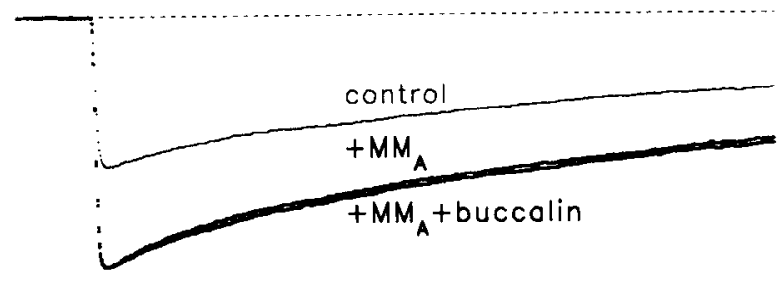

Figure 8. The presynaptic modulator buccalin ${ }_{\mathrm{A}}$ has no effect on $\mathrm{Ba}$ current. Shown are $\mathrm{Co}^{2+}$-leak subtracted Ba currents eliciled in three different fibers by long $(5 \mathrm{sec})$ voltage steps from -90 to $0 \mathrm{mV}$ in $\mathrm{Ba}$ / TEA ASW. $a$, Buccalin at $_{\mathrm{A}} 1 \mu \mathrm{M}$ has no effect on the basal Ba current, and does not prevent its enhancement by $1 \mu \mathrm{M} 5$-HT. $b$ and $c$, Buccalin ${ }_{\mathrm{A}}$ at $1 \mu \mathrm{M}$ has no effect on Ba current already enhanced by $1 \mu \mathrm{M} 5-\mathrm{HT}$ or $\mathrm{MM}_{\mathrm{A}}$.

and occasionally even net outward current (even after $\mathrm{Co}^{2+}-$ leak subtraction) at the end of the voltage step (e.g., Fig. $9 \mathrm{Cb}$ ). Nevertheless, some increase in the rate of inactivation accompanied enhancement of the Ba current even in fibers with little obvious outward-current contamination (see further below), raising the possibility that at least some properties of the modulator-induced component of the current were in fact different from those of the preexisting current.

However, with respect to both the voltage dependence of steady-state inactivation (holding-potential dependence) and the sensitivity to nifedipine, the basal and enhanced Ba current appeared essentially indistinguishable. This was the case even in fibers in which the modulators enhanced the basal current by over $100 \%$ (e.g., Fig. $10 \mathrm{~A}$ ), so that more than half of the amplitude of the enhanced current was modulator-induced current, making detection of any significant differences in the properties of the basal and modulator-induced currents quite likely. Just like the basal current (see Fig. $4 A$ of Březina et al., 1994c), the enhanced current was fully available for activation from holding potentials more negative than $-70 \mathrm{mV}$, began to inactivate as the holding potential was depolarized past $-60 \mathrm{mV}$, and was half-inactivated at about $-45 \mathrm{mV}$ (Fig. 10 $A$, three fibers).

With nifedipine, too, the enhanced current was blocked with virtually the same potency and characteristic time dependenceprogressive increase in the strength of the block during the voltage step-that we previously found for the basal current (Fig. $8 A$ of Březina et al., 1994c). Thus, $10 \mathrm{~nm}$ to $1 \mu \mathrm{M}$ nifedipine had little effect on the peak enhanced current but blocked the current at the end of a $5 \mathrm{sec}$ step by $5-70 \% ; 10 \mu \mathrm{M}$ substantially reduced the peak current, too, and 20-50 $\mu \mathrm{M}$ almost completely eliminated even the remaining initial current transient (Fig. 11 A; three fibers with currents enhanced by $5-\mathrm{HT}$ or $\mathrm{SCP}_{\mathrm{B}}$ ). Such time dependence is a characteristic feature of dihydropyridine Ca-channel antagonist action, generally ascribed to a preferential interaction of these compounds with some state of the channel promoted by depolarization, for instance a gradual openchannel block or an increase in the rate of transition to the normal inactivated state (see Březina et al., 1994c). (In the earlier article, we considered but ultimately found unconvincing the idea that the nifedipine block revealed two different $\mathrm{Ca}$ currents.) Evidently, neither this nor any other significant aspect of the nifedipine interaction with the ARC-muscle Ca channels was altered by their modulation. Likewise, in the converse experiment, prior application of intermediate concentrations of nifedipine to partially block the basal Ba current did not prevent its subsequent enhancement by the modulators. Indeed, their intrinsic action appeared completely unaffected: the remaining current was (as already mentioned) quite normally simply scaled up by the usual $50-100 \%$ without obvious change in its (now nifedipine-modified) kinetics (Fig. $11 \mathrm{Ba}, \mathrm{Bb}$; four fibers were tested with 5-IIT, $\mathrm{SCP}_{\mathrm{B}}$, and $\mathrm{MM}_{\mathrm{A}}$ ). However, the modulators could not overcome the nifedipine block: as the nifedipine concentration was increased, the ahsolute amplitude of the current induced by the modulators decreased in parallel with that of the basal current, and eventually, when all of the basal current had been blocked, so was the modulation (Fig. $11 B C$, three fibers). The nifedipine block and the enhancement thus appeared mutually independent.

As with the basal current (Březina et al., 1994c), we failed to observe any obvious potentiation of the enhanced $\mathrm{Ba}$ current by $10 \mathrm{nM}$ to $10 \mu \mathrm{M}$ of the dihydropyridine Ca-channel agonist Bay K 8644 (two fibers). Similarly, up to $10 \mu \mathrm{M} \omega$-conotoxin GVIA or $\omega$-conotoxin MCVII or up to $1 \mu \mathrm{M} \omega$-agatoxin IVA, three toxins that block non-"L" $\mathrm{Ca}$ channels in vertebrates but not the basal Ba current in the AKC muscle fibers (Brezina et al., 1994c), had no effect on the enhanced current (two or three fibers each).

Finally, even the increased rate of inactivation of the enhanced current, in the simplest interpretation, in fact supported the hypothesis that the enhancement was simply of the preexisting "L"-type current. Earlier, we reported that this current inactivates, more strongly when carried by $\mathrm{Ca}^{2+}$ but even when carried by $\mathrm{Ba}^{2+}$, by a current-dependent mechanism, that is, feedback inhibition of the current by the elevated intracellular concentration of $\mathrm{Ca}^{2+}$ or $\mathrm{Ba}^{2+}$ resulting from the flow of the current itself (Březina et al., 1994c). The rate of inactivation thus depends on the amplitude of the current, and any manipulation that increases the amplitude speeds the inactivation. In the earlier work, for example, when the extracellular $\mathrm{Ba}^{2+}$ concentration was elevated so as to double the peak amplitude of the $\mathrm{Ba}$ current, its rate of inactivation increased considerably (Fig. 7 of Březina et al., 1994c). Indeed, it increased to a degree 
A

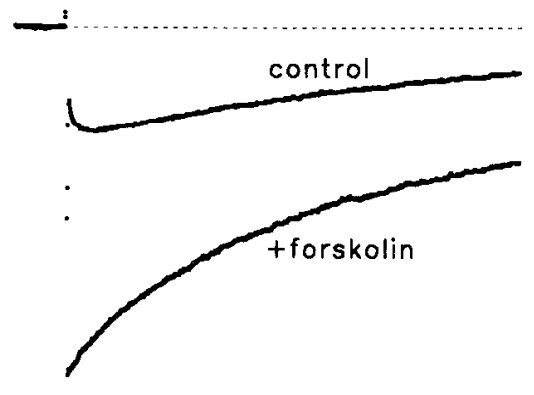

B

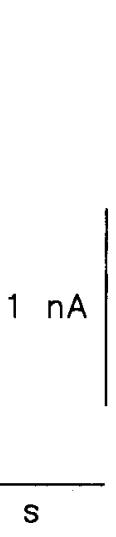

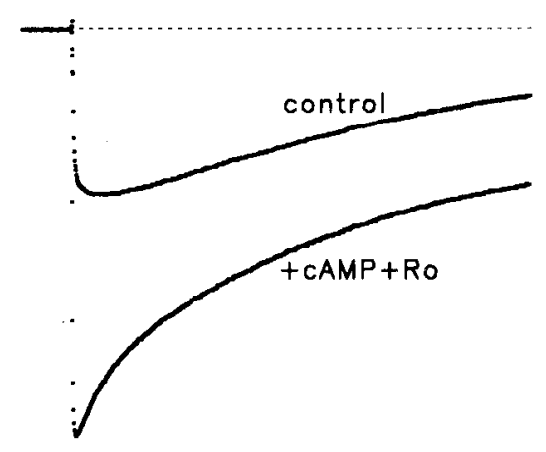

$2 s$

\section{$\mathrm{Co}$}

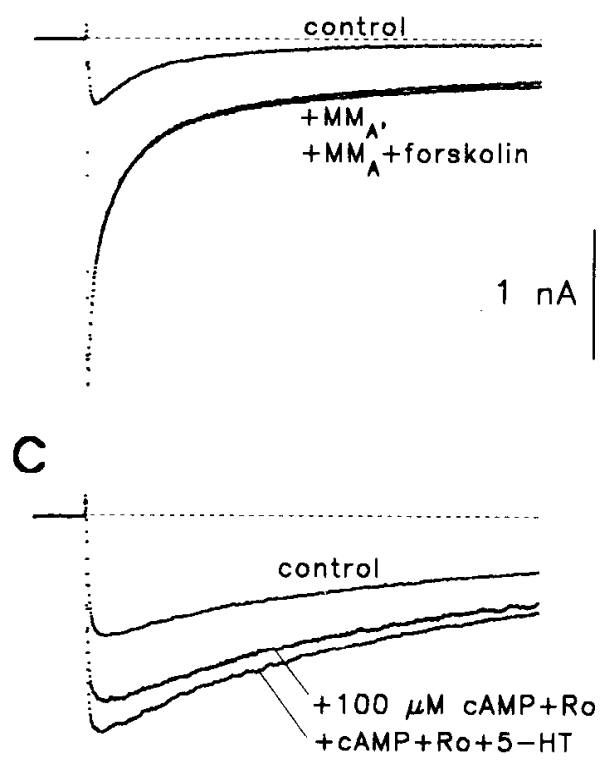

b

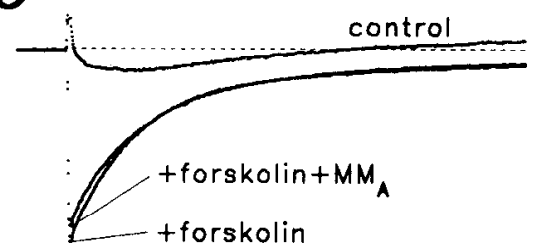

d

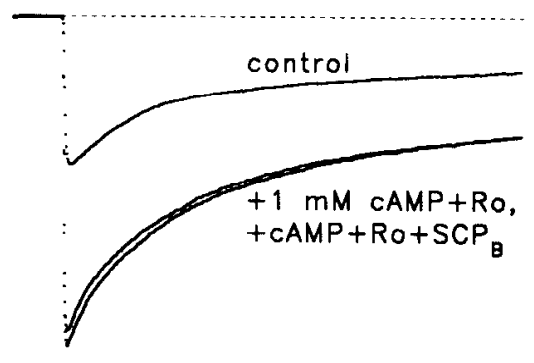

Figure 9. Elevation of cAMP mimics and occludes the modulator-induced enhancement of Ba current. All of the currents shown are $\mathrm{Co}^{2+}$-leak subtracted $\mathrm{Ba}$ currents elicited by long $(5 \mathrm{sec}$ ) voltage steps from -90 to $0 \mathrm{mV}$ in $\mathrm{Ba}$ TEA ASW. $A$, Enhancement by $50 \mu \mathrm{M}$ forskolin. $B$, Enhancement $15 \mathrm{~min}$ after application of $100 \mu \mathrm{M}$ CPT-cAMP together with $100 \mu \mathrm{M}$ Ro 20-1724. C, Examples of occlusion experiments. $C a$ and $C b$, The effects of $1 \mu \mathrm{M} \mathrm{MM}_{\mathrm{A}}$ and $50 \mu \mathrm{M}$ forskolin are mutually occlusive. $C c$ and $C d, C P T-c A M P$ at $100 \mu \mathrm{M}$ (plus $100 \mu \mathrm{M}$ Ro $20-1724$ ) only partially occludes the effect of $1 \mu \mathrm{M}$ 5-HT $(C c)$, whereas 1 mм CPT-cAMP (plus $100 \mu \mathrm{M}$ Ro 20-1724) is able to fully occlude the effect of a modulator $(C d)$, in this case $1 \mu_{\mathbf{M ~ S C P}}$. that was not significantly different than when the amplitude of the current was doubled by a modulator (e.g., Fig. 10B). Thus, it appeared that the rate of inactivation of the current was determined simply by its amplitude irrespective of whether or not it had been enhanced; enhancement speeded the current's inactivation only because it made the current larger. There was no need to suppose that the modulators induced a new current with inactivation properties different from those of the preexisting " $L$ "-type current, or indeed affected the inactivation of the " $L$ "-type current in any intrinsic way.

To confirm this conclusion, we carried out experiments in which we first enhanced the amplitude and speeded the inactivation of the Ba current with a modulator and then, in the continued presence of the modulator, reduced the current again by lowering the extracellular $\mathrm{Ba}^{2+}$ concentration (from the normal $11 \mathrm{mM}$ to 7 or $4 \mathrm{~mm}$ ) or by adding increasing concentrations of the Ca-channel blockers $\mathrm{Cd}^{2+}(10-100 \mu \mathrm{M})$ or $\mathrm{Co}^{2+}(1-3 \mathrm{mM})$. We found that when the amplitude of the enhanced current was reduced again to about the basal level, its inactivation often likewise reassumed almost exactly its original kinetics (Fig. 10B, four fibers). The simplest conclusion was that the whole enhanced current had "L"-like inactivation characteristics and thus was most likely indeed homogeneous " $L$ "-type current (but see Discussion). Otherwise, the $\mathrm{Cd}^{2+}, \mathrm{Co}^{2+}$, and reduced $\mathrm{Ba}^{2+}$ would have had to block completely the modulator-induced component of the current but leave the basal component completely unaffected. However, these treatments reduce current through most known types of Ca channels rather indiscriminatcly; furthcrmorc, our earlier work showed that they all reduce the basal ARC-muscle current just as potently as the modulatorenhanced current (Březina et al., 1994c).

\section{Receptor pharmacology}

Our finding that all of the postsynaptic modulators acted identically in enhancing the $\mathrm{Ca}$ or $\mathrm{Ba}$ current might hypothetically have been due to their all acting at the same cell-surface receptor. Certainly, previous pharmacological characterization of receptors for various signaling molecules in mollusks (reviewed by S.-Rózsa, 1984) would predict separate receptors for each modulator family - the SCPs, the MMs, and 5-HT - though probably not for different members of the same family (but see the following article, Březina et al., 1994d). Moreover, Lloyd et al. (1984) observed some additivity between even maximal effects of 5-HT and $\mathrm{SCP}_{\mathrm{B}}$ on cAMP levels in the ARC muscle, sug- 
A

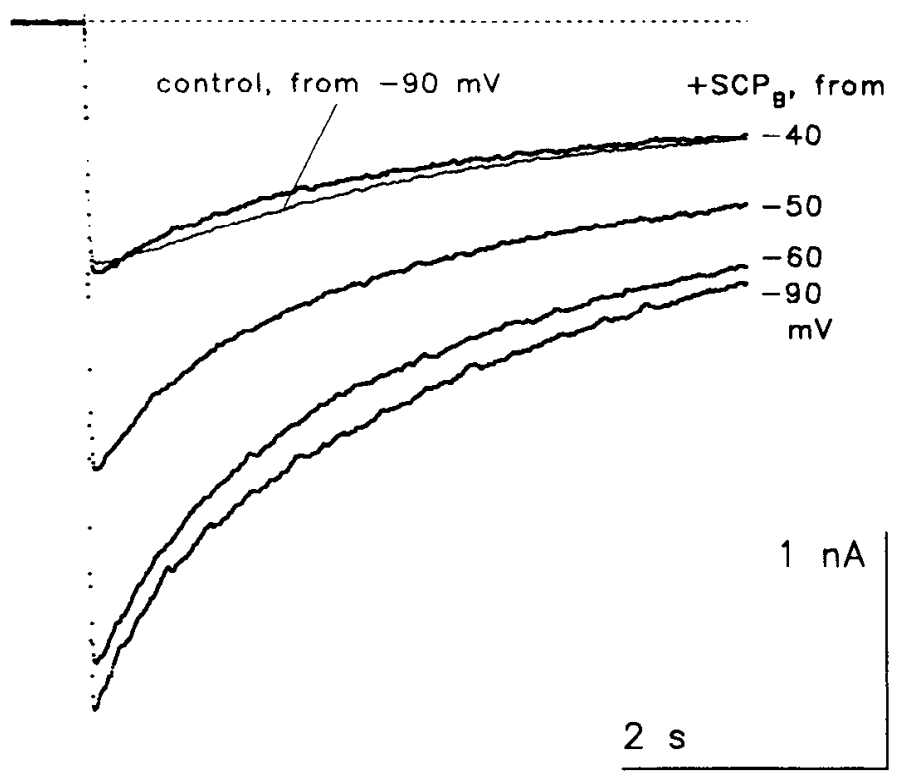

B

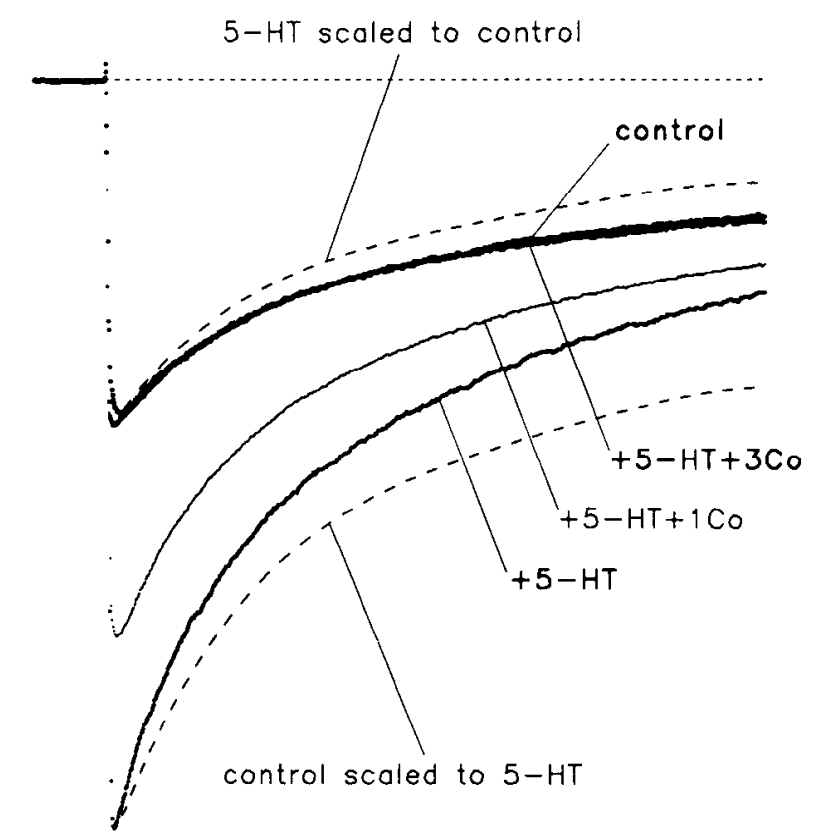

Figure 10. Enhancement does not alter the holding-potential dependence of the Ba current; the faster inactivation of the enhanced current can be explained simply by its larger size. Shown are $\mathrm{Co}^{2+}$-leak subtracted Ba currents elicited by long ( $5 \mathrm{sec}$ ) voltage steps from $-90 \mathrm{mV}(B)$ or a range of holding potentials $(A)$ to $0 \mathrm{mV}$ in Ba/TEA/4-AP ASW. $A$, Holding-potential dependence. The step was given first from - $90 \mathrm{mV}$, and then the current was enhanced by $1 \mu \mathrm{M} \mathrm{SCP}_{\mathrm{B}}$ and the step given again from $-90,-60,-50$, and $-40 \mathrm{mV}$. The holding-potential dependence of the enhanced current is essentially identical to that of the basal, unmodulated Ba current shown in Figure $4 A$ of our earlier article (Březina et al., 1994c). $B$, Inactivation kinetics. The Ba current was recorded first under control conditions, then enhanced by $1 \mu \mathrm{M} 5-\mathrm{HT}$, and then progressively blocked again by 1 and $3 \mathrm{~mm} \mathrm{Co}^{2+}$ added to the bath. The enhanced current inactivates faster during the voltage step than the basal current, as can be seen by scaling the basal current to the peak amplitude of the enhanced current (control scaled to 5-HT). However, the same is observed whenever Ba currents are made larger by any other means (compare, e.g., Fig. 7 of Brrezina et al., 1994c). Indeed, when the current is reduced again by $\mathrm{Co}^{2+}$ even in the continued presence of $5-\mathrm{HT}$, its inactivation slows again; the current in $3 \mathrm{mM} \mathrm{Co} \mathrm{Co}^{2+}$ has about the same peak amplitude as the initial unmodulated current, and a virtually identical trajectory of inactivation. (If the inactivation had remained fast, the blocked current would have inactivated along the 5-HT scaled to control trajectory.)

gesting distinct receptors for at least $5-\mathrm{HT}$ and $\mathrm{SCP}_{\mathrm{B}}$. Nevertheless, in view of the similarity of the modulators' effects, further confirmation of the presence of separate ARC-muscle receptors seemed desirable, and might provide tools for further study of the roles of the various modulators in the physiological control of the ARC muscle.

However, we were unsuccessful in finding pharmacological agents that would separate the effects of the different modulators on the $\mathrm{Ca}$ or Ba current. Selective agonists and antagonists of SCP and MM receptors are not yet available. Therefore, we tested agents that have been reported effective in blocking cAMPlinked 5-HT receptors in Aplysia. In membrane homogenates from Aplysia pleural ganglia, $10 \mu \mathrm{M}$ ketanserin or ritanserin markedly inhibits adenylyl-cyclase stimulation by $5 \mu \mathrm{M} 5-\mathrm{HT}$ but not $\mathrm{SCP}_{\mathrm{B}}$ (Ocorr and Byrne, 1986); in Aplysia sensory neurons, $200 \mu \mathrm{M}$ cyproheptadine blocks electrophysiological effects mediated by one class of 5-HT receptors that may be cAMPlinked (Mercer et al., 1991); and in the cardiovascular musculature of Aplysia, $1 \mathrm{~mm}$ methysergide blocks 5-HT-induced contraction and clevation of cAMP (Sawada et al., 1984). In the ARC muscle fibers, however, these agents were not useful as 5-HT receptor antagonists. Methysergide had no effect at 10 $\mu_{\mathrm{M}}$, but at $100 \mu_{\mathrm{M}}$ to $1 \mathrm{mM}$ it proved to be an agonist: it enhanced the Ba current about as much as maximal concentrations of 5-HT usually did, and indeed occluded the effect of $10 \mu \mathrm{M} 5-\mathrm{HT}$ (five fibers). The other agents acted rather like nifedipine (see
Fig. 11): although they often blocked the basal (and indeed the enhanced) $\mathrm{Ba}$ current in a time-dependent manner, they did not prevent or apparently even consistently reduce enhancement of the remaining current by 5 -HT. Thus, $100 \mu \mathrm{M}$ ketanserin reversibly suppressed the peak (basal or 5-HT-enhanced) Ba current by $30-50 \%$, the current $200 \mathrm{msec}$ into the voltage step by $50-80 \%$, and the current after 1 sec by $80-90 \%$, but did not prevent enhancement of the remaining basal current by about the usual $50-100 \%$ by $1-10 \mu \mathrm{M} 5-\mathrm{HT}$ (four fibers). Poor solubility prevented us from testing ritanserin in these experiments, but even at $100 \mu \mathrm{M}$ it (as indeed all of the agents) proved ineffective as an antagonist of the second effect of 5-HT described in the following article (Březina et al., 1994d). Finally, $100 \mu \mathrm{M}$ cyproheptadine suppressed the (basal or 5-HT-enhanced) Ba current by $10 \%$ at its peak, $30 \%$ after $200 \mathrm{msec}$, and $60 \%$ after $1 \mathrm{sec} ; 500 \mu \mathrm{M}$ suppressed the peak current by $30-50 \%$ and the current after $200 \mathrm{msec}$ by $50-80 \%$. However, even $500 \mu \mathrm{M}$ cyproheptadine did not prevent considerable enhancement of the remaining basal current by 1-10 $\mu \mathrm{M} 5$-HT (three fibers).

\section{Discussion}

The dissociated ARC muscle fihers are functionally intact All indications were that our dissociated fibers retained to a high degree the native properties and physiological function of fibers in situ in the intact ARC muscle, and that our recording with sharp microelectrodes disturbed those properties minimally. In 
A

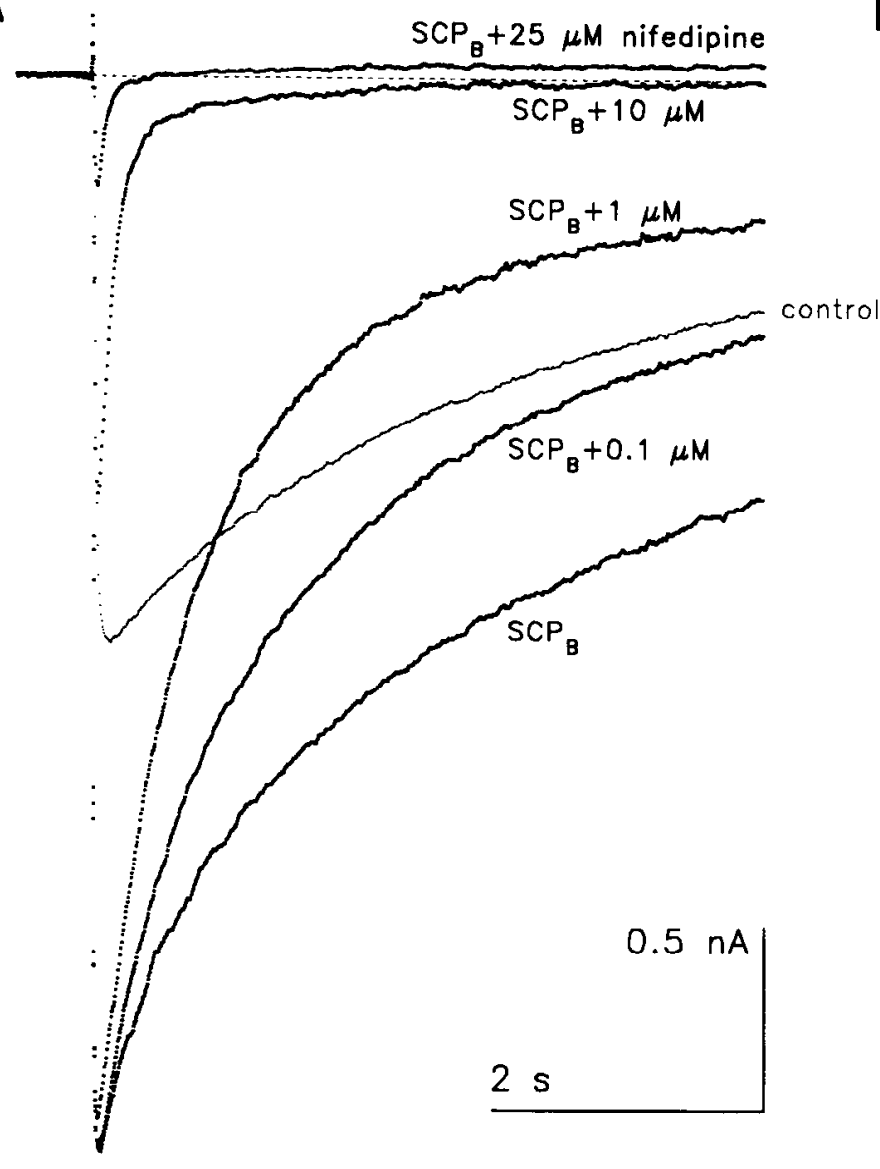

B a

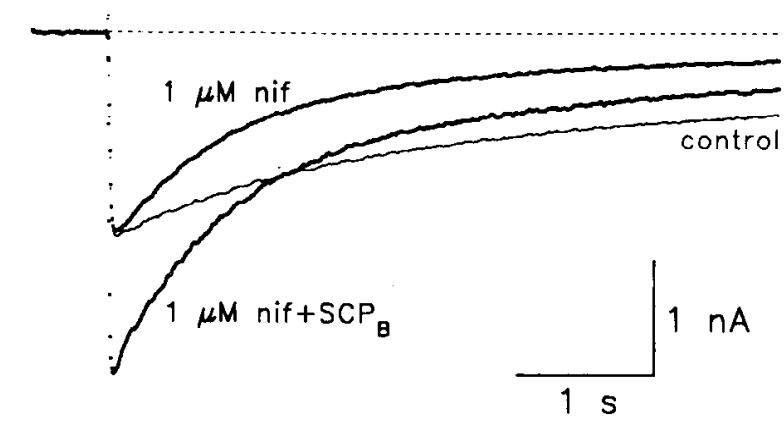

b

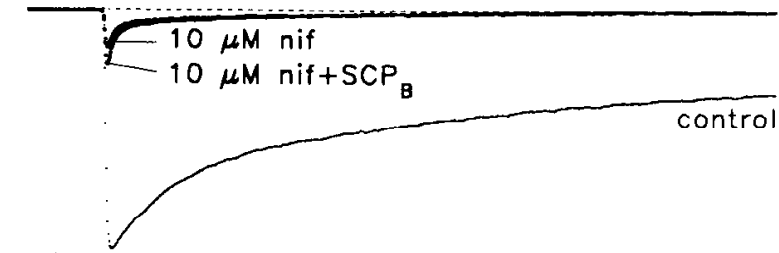

C

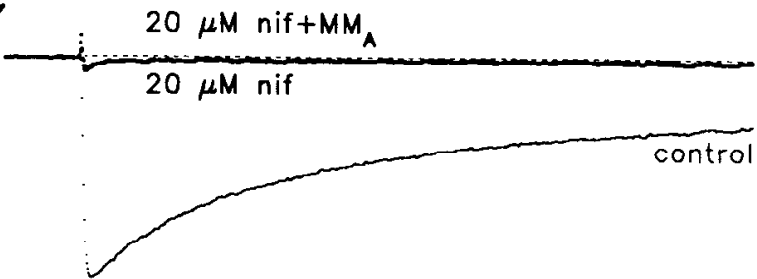

Figure 11. Enhancement does not alter the sensitivity of the Ba current to nifedipine; enhancement and nifedipine block are mutually independent. All of the currents shown are $\mathrm{Co}^{2+}$-leak subtracted Ba currents elicited by long $(5 \mathrm{sec})$ voltage steps from -90 to $0 \mathrm{mV}$ in Ba/TEA ASW. $A$, Current enhanced by $1 \mu \mathrm{M} \mathrm{SCP}_{\mathrm{B}}$ is blocked by application of successively higher concentrations of nifedipine with about the same potency and time dependence as the basal, unmodulated Ba current usually is (compare Fig. $8 A$ of Březina et al., 1994c). $B$, In the converse experiment, the modulators (at $1 \mu \mathrm{M})$ are still able to enhance quite normally whatever $\mathrm{Ba}$ current remains unblocked by intermediate concentrations of nifedipine ( $B a$ and $B b$ ), but when all of the basal current is blocked, so is the modulation ( $B c ; a-c$ from different fibers). Thus, the intrinsic action of the modulators appears unaffected by nifedipine, but cannot overcome the nifedipine block.

our earlier articles (Březina et al., 1994a-c), we described a variety of ion currents present in the fibers whose properties plausibly explain much of the electrical and mechanical behavior of the muscle. The fibers readily contract when depolarized by current injection, high-K ${ }^{+}$solution (Březina and Weiss, 1993; Březina et al., 1994a) or the natural contraction-inducing transmitter ACh (Fig. 1A; Březina and Weiss, 1993; further work is in progress). Most importantly, we have shown here that the fibers pass the most demanding functional test: the physiological postsynaptic modulators, the SCPs, MMs, and 5-HT, are able to potentiate and depress contractions of single fibers just like those of the whole ARC muscle. (This result incidentally confirms unambiguously that a major site of the modulation is indeed postsynaptic.) All of the mediating cellular mechanisms must therefore still be intact, among them, we propose (see below), the elevation in cAMP that the modulators indeed induce in the dissociated fibers (Fig. 2) just as in the whole ARC muscle, and the modulation of the $\mathrm{Ca}$ and $\mathrm{K}$ currents that we have studied here and in the following article (Březina et al., 1994d). In remaining fully functional following dissociation, the ARC muscle fibers resemble many other molluscan (Ishii et al., 1988, 1989; Zoran et al., 1989; Cawthorpe and Lukowiak, 1990) and indeed vertebrate (e.g., Lassignal et al., 1986; Benham and
Tsien, 1988; Nelson et al., 1988; Goto et al., 1989) muscle fibers that likewise retain their contractility and normal electrical and mechanical responses to transmitters and modulators, explaining why dissociated fibers are often the preparation of choice in muscle physiology. All of these considerations suggest that our study of the modulation of ion currents and contractions of the dissociated fibers might provide a solid basis for understanding the in vivo physiology of the intact ARC muscle.

\section{Modulation of Ca channels}

Enhancement or suppression of Ca current is a ubiquitous modulatory mechanism in many muscle cells and neurons of both invertebrates and vertebrates (for review, see, e.g., Hofmann et al., 1987; Tsien, 1987; Rosenthal et al., 1988; Scott et al., 1991). Indeed, one of the signal characteristics of " $L$ "-type Ca channels is the maintenance and enhancement of their activity by cAMPdependent phosphorylation (Hofmann et al., 1987; Armstrong, 1989). Aplysia and other molluscan neurons possess predominantly " $L$ "-type Ca currents very like the ARC-muscle current, and in a number of them enhancement much like that described here has been reported, often similarly in response to the CAMPelevating agents $5-\mathrm{HT}$ and $\mathrm{SCP}_{\mathrm{B}}$ and most likely mediated by cAMP (more rarely, cGMP or protein kinase C; e.g., Pellmar, 
1984; DeRiemer et al., 1985; Paupardin-Tritsch et al., 1986; Levitan et al., 1987; Acosta-Urquidi, 1988; Furukawa and Kobayashi, 1988; Jansen and Mayeri, 1988; Levitan and Levitan, 1988; Lotshaw and Levitan, 1988; Braha et al., 1993). Similar enhancement of " $L$ "-type Ca current has been described in vertebrate smooth (e.g., Benham and 'I'sien, 1988; Goto et al., 1989) and skeletal (Arreola et al., 1987) muscle. However, the phenomenon is best understood in vertcbrate cardiac muscle. There, as in the ARC muscle fibers, the " $\mathrm{L}$ "-type Ca current is similarly enhanced by several cAMP-elevating neurotransmitters (classically studied have been $\beta$-adrenergic agonists) and modulatory peptides (Hescheler et al., 1987; Tsien, 1987; Sperelakis, 1988; Ono et al., 1989; Méry et al., 1990).

On the single-channel level, the enhancement of the cardiac "L"-type Ca current appears as a greater number of channels available for activation as well as an increased rate of opening and a decreased rate of closing of the active channels (reviewed by Tsien, 1987). Similar single-channel mechanisms have been reported in the crayfish tonic flexor muscle, where enhancement of the activity of two types of Ca channels by the peptide cotransmitter proctolin (Bishop et al., 1991) may underlie potentiation of contractions of the muscle strikingly analogous to the modulation in the ARC-muscle system (Bishop et al., 1987). The simple scaling up of the current that we find in the ARC muscle fibers is certainly compatible with an increase both in the number of activatable "L"-type channels and in the fraction of the time that each active channel spends open (as well as increased single-channel conductance, though this is not a common mechanism of channel modulation). However, it would be premature to rule out completely the possibility of recruitment of covert Ca channels different from those carrying the preexisting current. The basal ARC-muscle Ca current appears homogeneously "I."-like (Březina et al., 1994c), and the modulatorinduced current component is indistinguishable from it in all properties that we have examined, most importantly the voltage dependence of its activation and steady-state inactivation, its kinetics when carried by $\mathrm{Ca}^{2+}$ and $\mathrm{Ba}^{2+}$, the current dependence of its inactivation, and its block by nifedipine. Thus, unlike, for example, Edmonds et al. (1990) in Aplysia sensory neurons, we cannot conclude that the ARC muscle fibers possess different Ca-current components that are differentially modulated. Nevertheless, the example of Aplysia bag cells is instructive. In these neurons, the macroscopic Ca current enhanced by protein kinase $C$ appears, as in our experiments, indistinguishable from the basal current (DeRiemer et al., 1985). Single-channel recordings, however, reveal that the basal and newly induced currcnts arc nevertheless carried by $\mathrm{Ca}$ channels quite different in conductance and distribution on the cell surface (Strong et al., 1987). Single-channel experiments will thus clearly be required to answer definitively the question also in the ARC muscle fibers.

\section{Role of $C A M P$}

The SCPs, MMs and 5-HT all elevate cAMP in the ARC muscle (Weiss et al., 1979; Lloyd et al., 1984; Whim and Lloyd, 1989; Hooper et al., 1992; our data in Fig. 2), activate cAMP-dependent protein kinase (PKA), and phosphorylate several common protein substrates (Hooper et al., 1991, 1992; Probst et al., 1992; Weiss et al., 1992). Potentiation of both the amplitude and relaxation rate of $\mathrm{ARC}$-muscle contractions is mimicked by forskolin and cAMP analogs (Weiss et al., 1979; Ram et al., 1984a; Hooper et al., 1991), and potentiation of the contractions following MCC stimulation is enhanced and prolonged by the phosphodiesterase inhibitor Ro 20-1724 (Weiss et al., 1979). Taken together, this evidence strongly suggests that the modulators potentiate the amplitude and relaxation rate of $\mathrm{ARC}$ muscle contractions via the $\mathrm{CAMP} / \mathrm{PKA}$ second-messenger pathway. Our finding that forskolin and CAMP mimic the modulator-induced enhancement of the Ca current, together with the known link between cAMP-dependent phosphorylation and activity of "L"-type $\mathrm{Ca}$ channels, suggests that the modulators enhance the Ca current likewise via cAMP. (Nevertheless, experiments with blockers of the cAMP/PKA pathway will be required to confirm that the pathway is necessary for the modulation of the current or indeed of the contractions.) The severalfold elevation in cAMP by $\mathrm{MM}_{\mathrm{A}}$ or forskolin (Fig. $2 b$ ) evidently suffices for maximal enhancement, since the much higher cAMP levels attained with 5-HT or SCP (Fig. 2a) do not enhance the current further (e.g., Fig. 7Bb). Enhancement of the $\mathrm{Ca}$ current via cAMP is as expected if indeed the enhancement is a major mechanism underlying the potentiation of contractions by the modulators (see next section). In contrast, the second effect of the modulators described in the following article, activation of a $\mathrm{K}$ current that we suggest depresses the contractions, is not substantially mimicked by forskolin or cAMP (Březina et al., 1994d), and is thus presumably mediated by a cellular mechanism other than the $\mathrm{CAMP} / \mathrm{PKA}$ pathway.

\section{Enhancement of the Ca current as a mechanism of the potentiation of contractions}

We propose that the enhancement of the $\mathrm{Ca}$ current by the postsynaptic modulators is a major mechanism by which they potentiate the amplitude of ARC-muscle contractions. Ample precedent exists for such a mechanism. Contraction requires entry of extracellular $\mathrm{Ca}^{2+}$ in many muscle types, and even where basal contractions are due primarily to release of $\mathrm{Ca}^{2+}$ from intracellular stores, they are often potentiated by an enhanced influx of extracellular $\mathrm{Ca}^{2+}$. This may play an important role even in vertebrate skeletal muscle (Arreola et al., 1987). The classical example, however, is vertebrate cardiac muscle, where the enhancement of "L"-type Ca current by $\beta$-adrenergic agonists and other cAMP-stimulating modulators (see above) potentiates several parameters including the strength of contractions of the heart (Tsien, 1987; Sperelakis, 1988), and suppression of (particularly the enhanced) current by $\mathrm{ACh}$ and adenosine contributes to their opposite effects (Löffelholz and Pappano, 1985; Sperelakis, 1988). In vertebrate smooth muscle, which molluscan feeding muscles such as the ARC resemble perhaps most closely in their morphology, ultrastructure, and slow maintained contractions (Hoyle, 1983; see Březina et al., 1994a), enhancement of Ca current, indeed often cAMP-dependent enhancement of "L"'-type current, similarly potentiates contractions (Bülbring and Tomita, 1987; Benham and Tsien, 1988; Nelson et al., 1988; Vivaudou et al., 1988; Clapp et al., 1989; Goto et al., 1989). In both smooth and cardiac muscle, contractions are effectively inhibited by dihydropyridines and other Ca-channel blockers (reviewed by Janis et al,, 1987). Finally, although intracellular $\mathrm{Ca}^{2+}$ sources may contributc, cntry of extracellular $\mathrm{Ca}^{2+}$ appears important for physiological contraction of many molluscan muscles. ACh-(but not caffeine-) elicited contractions are quickly abolished in $\mathrm{Ca}^{2+}$-free solution and suppressed by Ca-channel blockers (e.g., Hill et al., 1970; Hill and McDonald-Ordzie, 1979; Ram et al., 1984b; Gole et al., 1987; Ishii et al., 1988, 1989; Alohan, 1991; Huddart et al., 
1992). The clcvation of intraccllular $\mathrm{Ca}^{2+}$ by cholinergic agonists that presumably underlies the contractions is likewise suppressed by these treatments (Ishii et al., 1988, 1989).

Similar evidence exists for the ARC muscle itself. $\mathrm{ACh}$ increases ${ }^{45} \mathrm{Ca}^{2+}$ influx into the muscle (Ram and Parti, 1985), and our preliminary experiments (Březina and Weiss, 1993) have shown that $\mathrm{ACh}$-induced contractions of the dissociated fibers are completely blocked when extracellular $\mathrm{Ca}^{2+}$ is removed or nifedipine added at about the concentrations at which it blocks the "L"-type Ca current. Furthermore, when the AChinduced depolarization is clamped below the activation threshold of the Ca current, no contraction occurs. ACh-induced contractions appear in these respects no different than contractions induced by simply depolarizing the fiber beyond the Ca-current threshold by current injection or high- $\mathrm{K}^{+}$solution. Thus, the " $L$ "-type Ca current apparently provides $\mathrm{Ca}^{2+}$ essential for even ACh-induced contraction of the $\mathrm{ARC}$ muscle; while additional $\mathrm{Ca}^{2+}$ may enter through the ACh-receptor channels themselves (e.g., Mulle et al., 1992) or be released from intracellular stores (cf. Twarog and Muneoka, 1972; Gole et al., 1987), such $\mathrm{Ca}^{2+}$ is, by itself, insufficient for contraction. Earlier, we estimated that flow of the "L"-type Ca current during physiological contraction may elevate intracellular $\mathrm{Ca}^{2+}$ in the ARC muscle to (without allowing for intracellular buffering, however) as much as $10 \mu \mathrm{M}$ (Březina et al., 1994c), a concentration quite sufficient to contract strongly vertebrate smooth muscle (e.g., Bolton, 1979; Grover and Daniel, 1985) and indeed skinned molluscan muscle (Cornelius, 1980; Ram and Patel, 1989), and fully able to account for the relatively modest elevation in $\mathrm{Ca}^{2+}$ actually measured in molluscan muscle during contractions induced by cholinergic agonists or high-K+ solution (Ishii et al., 1988, 1989).

If the "L"-type $\mathrm{Ca}$ current supplies the $\mathrm{Ca}^{2+}$ that contracts the ARC muscle, it seems likely that the enhancement of the current by the modulators would potentiate the amplitude of the contractions. Experiments to confirm directly that this is indeed how the modulators act are in progress, but several observations are already encouraging. The concentrations at which the modulators enhance the Ca current (Fig. $6 \mathrm{~B}$ ) match reasonably well those at which they potentiate the contractions (Lloyd et al., 1984; Cropper et al., 1987, 1991). Potentiation by 5-HT requires extracellular $\mathrm{Ca}^{2+}$, and $1 \mu \mathrm{M} 5$ - $\mathrm{HT}$ enhances ${ }^{45} \mathrm{Ca}^{2+}$ influx into the muscle 2.5-fold (Ram et al., 1984b), consistent with the doubling of the Ca current in our experiments. The modulators potentiate $\mathrm{ACh}$-independent contractions induced by electrical stimulation (Ram et al., 1984a), high-K ${ }^{+}$solution, or intracellular current injection (Březina and Weiss, 1993) just like ACh-induced contractions, but fail to potentiate contractions induced by agents that bypass activation of the Ca current, such as caffeine or the $\mathrm{Ca}^{2+}$-ionophore A23187 (Gole et al., 1987; Březina and Weiss, 1993).

Similar mechanisms may underlie the often strikingly similar potentiation of contractions that cAMP-elevating agents such as 5 -HT and $\mathrm{SCP}_{\mathrm{B}}$, as well as other peptide modulators present as cotransmitters in presynaptic motor neurons, induce in other Aplysia buccal-mass muscles (Lotshaw and Lloyd, 1990), other molluscan muscles (in somc, cnhancement of Ca spikes has been noted; Twarog and Muneoka, 1972; Lloyd, 1980; Muneoka and Kamura, 1982; Lloyd et al., 1985; Zoran et al,, 1989; Muneoka et al., 1991; Muneoka and Kobayashi, 1992), and muscles of other invertebrates (e.g., Kravitz et al., 1980; Evans and Myers, 1986; Calabrese, 1989; Watson and Groome, 1989). We have already mentioned the crayfish tonic flexor muscle preparation, where potentiation of contractions following release of the peptide cotransmitter proctolin from presynaptic motor neurons has indeed been proposed to be due to proctolinergic enhancement of Ca-channel activity in the muscle (Bishop et al., 1987, 1991).

At present we have no candidate mechanism to explain the increase in relaxation rate that accompanies the potentiation of contraction amplitude by the postsynaptic modulators. Modulators are often found to act at multiple sites within a cell, and it may be that, in addition to enhancing the Ca current, the postsynaptic modulators affect also some of the many other processes that interact to determine the level of intracellular free $\mathrm{Ca}^{2+}$ (for review, see van Breemen and Saida, 1989), or even act directly on the contractile apparatus (cf. Kamm and Stull, 1989; Pucéat et al., 1992). Indeed, we cannot yet be sure that such intracellular actions do not supplement the enhancement of the Ca current to contribute also to some extent to the potentiation of the amplitude of the contractions. Modulation of membrane ion currents does, however, appear to be a fundamental mechanism in the ARC muscle: in the following article, we propose activation of a $\mathrm{K}$ current as the mechanism by which the modulators depress the contractions (Březina et al., 1994d).

\section{References}

Acosta-Urquidi J (1988) Modulation of calcium current and diverse $\mathrm{K}^{+}$currents in identified Hermissenda neurons by small cardioactive peptide B. J Neurosci 8:1694-1703.

Alohan FI (1991) Dependence upon external calcium for contractile activity in two molluscan proboscis muscles. Comp Biochem Physiol 98C:369-376.

Armstrong DL (1989) Calcium channel regulation by calcineurin, a $\mathrm{Ca}^{2+}$-activated phosphatase in mammalian brain. Trends Neurosci $12: 117-122$

Arreola J, Calvo J, Garcia MC, Sánchez JA (1987) Modulation of calcium channels of twitch skeletal muscle fibres of the frog by adrenaline and cyclic adenosine monophosphate. J Physiol (Lond) 393: 307-330.

Benham CD, Tsien RW (1988) Noradrenaline modulation of calcium channels in single smooth muscle cells from rabbit ear artery. I Physiol (Lond) 404:767-784.

Bishop CA, Wine JJ, Nagy F, O'Shea MR (1987) Physiological consequences of a peptide cotransmitter in a crayfish nerve-muscle preparation. J Neurosci 7:1769-1779.

Bishop CA, Krouse ME, Wine JJ (1991) Peptide corransmitter potentiales calcium channel activity in crayfish skeletal muscle. J Neurosci 11:269-276.

Bolton TB (1979) Mechanisms of action of transmitters and other substances on smooth muscle. Physiol Rev 59:606-718.

Braha O, Edmonds B, Sacktor T, Kandel ER, Klein M (1993) The contributions of protein kinase $\mathrm{A}$ and protein kinase $\mathrm{C}$ to the actions of 5-HT on the L-type $\mathrm{Ca}^{2+}$ current of the sensory neurons in Aplysia. J Neurosci 13:1839-1851.

Březina V, Weiss KR (1993) Analysis of ion currents mediating modulation of contractions of the ARC muscle of Aplysia by simultaneous on-line length measurement and current/voltage clamp. Soc Neurosci Abstr 19:1262.

Březina V, Evans CG, Kupfermann I, Weiss KR (1991) Modulation of ion currents in the ARC muscle of Aplysia: convergent actions of serolonin, SCPs and myomodulins. Soc Neurosci Abstr 17:1305.

Březina V, Cropper EC, Evans CG, Kupfermann I, Weiss KR (1992) Enhancement of $\mathrm{Ca}$ and $\mathrm{K}$ currents by modulatory peptide cotransmitters correlated with potentiation and depression of contractions of the ARC muscle of Aplysia. Soc Neurosci Abstr 18:586.

Březina V, Evans CG, Weiss KR (1994a) Characterization of the membrane ion currents of a model molluscan muscle, the accessory radula closer muscle of Aplysia californica. I. Hyperpolarization-activated currents. J Neurophysiol, in press.

Březina V, Evans CG, Weiss KR (1994b) Characterization of the membrane ion currents of a model molluscan muscle, the accessory 
radula closer muscle of Aplysia californica. II. Depolarization-activated $\mathrm{K}$ currents. J Neurophysiol, in press.

Brezina V, Evans CG, Weiss KR (1994c) Characterization of the membrane ion currents of a model molluscan muscle, the accessory radula closer muscle of Aplysia californica. III. Depolarization-activated Ca current. J Neurophysiol, in press.

Březina V, Evans CG, Weiss KR (1994d) Activation of $\mathrm{K}$ current in the accessory radula closer muscle of Aplysia californica by neuromodulators that depress its contractions. J Neurosci 14:4412-4432.

Bülbring E, Tomita T (1987) Catecholamine action on smooth muscle. Pharmacol Rev 39:49-96.

Calabrese RL (1989) Modulation of muscle and neuromuscular junctions in invertebrates. Sem Neurosci 1:25-34.

Cawthorpe D, Lukowiak K (1990) Dopamine and FMRFamide act directly on isolated gill inuscle frbers in culture. Neurosci Lett 113 345-348.

Clapp LH, Vivaudou MB, Singer JJ, Walsh JV (1989) Substance P, like acetylcholine, augments one type of $\mathrm{Ca}^{2+}$ current in isolated smooth muscle cells. Pfluegers Arch 413:565-567.

Cohen JL, Weiss KR, Kupfermann I (1978) Motor control of buccal muscles in Aplysia. J Neurophysiol 41:157-180.

Cornelius $F$ (1980) The regulation of tension in a chemically skinned molluscan smooth muscle. J Gen Physiol 75:709-725.

Cropper EC, Lloyd PE, Reed W, Tenenbaum R, Kupfermann I, Weiss KR (1987a) Multiple neuropeptides in cholinergic motor neurons of Aplysia: evidence for modulation intrinsic to the motor circuit. Proc Natl Acad Sci USA 84:3486-3490.

Cropper EC, Tenenbaum R, Kolks MAG, Kupfermann I, Weiss KR (1987b) Myomodulin: a bioactive neuropeptide present in an identified cholinergic buccal motor neuron of Aplysia. Proc Natl Acad Sci USA 84:5483-5486.

Cropper EC, Miller MW, Tenenbaum R, Kolks MAG, Kupfermann I, Weiss KR (1988) Structure and action of buccalin: a modulatory neuropeptide localized to an identified small cardioactive peptidecontaining cholinergic motor neuron of Aplysia californica. Proc Natl Acad Sci USA 85:6177-6181.

Cropper EC, Miller MW, Vilim FS, Tenenbaum R, Kupfermann I, Weiss KR (1990a) Buccalin is present in the cholinergic motor neuron $\mathrm{Bl} 6$ of Aplysia and it depresses accessory radula closer muscle contractions evoked by stimulation of B16. Brain Res 512:175-179.

Cropper EC, Price D, Tenenbaum R, Kupfermann I, Weiss KR (1990b) Release of peptide cotransmitters from a cholinergic motor neuron under physiological conditions. Proc Natl Acad Sci USA 87:933-937.

Cropper EC, Vilim FS, Alevizos A, Tenenbaum R, Kolks MAG, Rosen S, Kupfermann I, Weiss KR (1991) Structure, bioactivity, and cellular localization of myomodulin B: a novel Aplysia peptide. Peptides 12:683-690.

DeRiemer SA, Strong JA, Albert KA, Greengard P, Kaczmarek LK (1985) Enhancement of calcium current in Aplysia neurones by phorbol ester and protein kinase C. Nature 313:313-316.

Edmonds B, Klein M, Dale N, Kandel ER (1990) Contribution of two types of calcium channels to synaptic transmission and plasticity. Science 250:1142-1147.

Evans PD, Myers CM (1986) Peptidergic and aminergic modulation of insect skeletal muscle. J Exp Biol 124:143-176.

Furukawa Y, Kobayashi M (1988) Modulation of ionic currents by synaptic action and 5-HT application in the identified heart excitatory neurone of the African giant snail, Achatina fulica Férussac. J Exp Biol 137:319-339.

Gole D, Munday L, Kreiman M, Ram JL (1987) Caffeine effects on buccal muscles of Aplysia. Comp Biochem Physiol 88C:313-318.

Goto K, Kasuya Y, Matsuki N, Takuwa Y, Kurihara H, Ishikawa T, Kimura S, Yanagisawa M, Masaki T (1989) Endothelin activates the dihydropyridine-sensitive, voltage-dependent $\mathrm{Ca}^{2+}$ channel in vascular smooth muscle. Proc Natl Acad Sci IJSA 86:3915-3918.

Grover AK, Daniel EE, eds (1985) Calcium and contractility: smooth muscle. Clifton, NJ: Humana.

Hescheler J, Tang M, Jastorff B, Trautwein W (1987) On the mechanism of histamine induced enhancement of the cardiac $\mathrm{Ca}^{2+}$ current. Pfluegers Arch 410:23-29.

Hill RB, McDonald-Ordzie PE (1979) Ionic dependence of the response to acetylcholine of a molluscan buccal muscle: the radular protractor of Busycon canaliculatum. Comp Biochem Physiol 62C: 19-30.

Hill RB, Greenberg MJ, Irisawa H, Nomura H (1970) Electrome- chanical coupling in a molluscan muscle, the radula protractor of Busycon canaliculatum. J Exp Zool 174:331-348.

Hofmann F, Nastainczyk W, Röhrkasten A, Schneider T, Sieber M (1987) Regulation of the L-type calcium channel. Trends Pharmacol Sci 8:393-398.

Hooper SL, Probst WC, Kupfermann I, Weiss KR (1991) SCP and myomodulin utilize separate signal transduction pathways and converge on common substrates in the ARC muscle of Aplysia. Soc Neurosci Abstr 17:1305.

Hooper SL, Cropper EC, Probst WC, Kupfermann I, Weiss KR (1992) Effects of neuron B16 stimulation and myomodulin application on cAMP and PKA levels in ARC muscle of $A$ plysia. Soc Neurosci Abstr 18:1105.

Hoyle G (1983) Muscles and their neural control. New York: Wiley.

Huddart H, Nelson ID, Brooks DD, Hill RB (1992) The calcium dependence of electrical and mechanical responses of the odontophore protractor muscle of Busycon canaliculatum. A sucrose-gap study of calcium antagonist action. Comp Biochem Physiol 102A:299-305.

Ishii N, Simpson AWM, Ashley CC (1988) Carbachol and KCl-induced changes in intracellular free calcium concentration in isolated fura-2 loaded smooth-muscle cells from the anterior byssus retractor muscle of Mytilus edulis. Biochem Biophys Res Commun 153:683689.

Ishii N, Simpson AWM, Ashley CC (1989) Effects of 5-hydroxytryptamine (serotonin) and forskolin on intracellular free calcium in isolated and fura-2 loaded smooth-muscle cells from the anterior byssus retractor (catch) muscle of Mytilus edulis. Pfluegers Arch 414:162-170.

Janis RA, Silver PJ, Triggle DJ (1987) Drug action and cellular calcium regulation. Adv Drug Res 16:309-591.

Jansen RF, Mayeri E (1988) The neuropeptide egg-laying hormone modulates multiple ionic currents in single target neurons of the abdominal ganglion of Aplysia. J Neurosci 8:3074-3084.

Kamm KE, Stull JT (1989) Regulation of smooth muscle contractile elements by second messengers. Annu Rev Physiol 51:299-313.

Kravitz EA, Glusman S, Harris-Warrick RM, Livingstone MS, Schwarz $T$, Goy MF (1980) Amines and a peptide as neurohormones in lobsters: actions on neuromuscular preparations and preliminary be* havioural studies. J Exp Biol 89:159-175.

Kupfermann I (1991) Functional studies of cotransmission. Physiol Rev 71:683-732.

Kupfermann I, Rosen S, Teyke T, Cropper EC, Miller M, Vilim F, Weiss KR (1989) Neurobiology of behavioral states in Aplysia: nonassociative forms of plasticity of feeding responses. In: Dynamics and plasticity in neuronal systems (Elsner N, Singer W, eds), pp 47-59. Stuttgart: Thieme.

Lassignal NL, Singer JJ, Walsh JV (1986) Multiple neuropeptides exert a direct effect on the same isolated single smooth muscle cell. Am J Physiol 250:C792-C798.

Laurenza A, Sutkowski EM, Seamon KB (1989) Forskolin: a specific stimulator of adenylyl cyclase or a diterpene with multiple sites of action? Trends Pharmacol Sci 10:442-447.

Levitan ES, Levitan IB (1988) Serotonin acting via cyclic AMP enhances both the hyperpolarizing and depolarizing phases of bursting pacemaker activity in the Aplysia neuron R15. J Neurosci 8:11521161.

Levitan ES, Kramer RH, Levitan IB (1987) Augmentation of bursting pacemaker activity by egg-laying hormone in Aplysia neuron R 15 is mediated by a cyclic AMP-dependent increase in $\mathrm{Ca}^{2+}$ and $\mathrm{K}^{+}$currents. Proc Natl Acad Sci USA 84:6307-6311.

Lieberman M, Hauschka SD, Hall ZW, Eisenberg BR, Horn R, Walsh JV, Tsien RW, Jones AW, Walker JL, Poenie M, Fay F, Fabiato F Ashley CC (1987) Isolated muscle cells as a physiological model. Am J Physiol 253:C349-C363.

Lloyd PE (1980) Modulation of neuromuscular activity by 5-hydroxytryptamine and endogenous peptides in the snail, Helix aspersa. J Comp Physiol 139:333-339.

Lloyd PE, Kupfermann I, Weiss KR (1984) Evidence for parallel actions of a molluscan neuropeptide and serotonin in mediating arousal in Aplysia. Proc Natl Acad Sci USA 81:2934-2937.

Lloyd PE, Kupfermann I, Weiss KR (1985) Two endogenous neuropeptides $\left(\mathrm{SCP}_{\mathrm{A}}\right.$ and $\left.S C \mathrm{P}_{\mathrm{B}}\right)$ produce a $\mathrm{CAMP}$-mediated stimulation of cardiac activity in Aplysia. J Comp Physiol [A] 156:659-667.

Löffelholz K, Pappano AJ (1985) The parasympathetic neuroeffector junction of the heart. Pharmacol Rev 37:1-24. 
Lotshaw DP, Levitan IB (1988) Reciprocal modulation of calcium current by serotonin and dopamine in the identified Aplysia neuron R15. Brain Res 439:64-76:

Lotshaw DP, Lloyd PE (1990) Peptidergic and serotonergic facilitation of a neuromuscular synapse in Aplysia. Brain Res 526:81-94.

Mercer AR, Emptage NJ, Carew TJ (1991) Pharmacological dissociation of modulatory effects of serotonin in Aplysia sensory neurons. Science 254:1811-1813.

Méry P-F, Brechler V, Pavoine C, Pecker F, Fischmeister R (1990) Glucagon stimulates the cardiac $\mathrm{Ca}^{2+}$ current by activation of adenylyl cyclase and inhibition of phosphodiesterase. Nature 345:158-161.

Mulle C, Choquet D, Korn H, Changeux J-P (1992) Calcium influx through nicotinic receptor in rat central neurons: its relevance to cellular regulation. Neuron 8:135-143.

Muneoka Y, Kamura M (1982) The multiplicity of neurotransmitters and neurohormones controlling Mytilus muscle. Comp Biochem Physiol 73C:149-156.

Muneoka Y, Kobayashi M (1992) Comparative aspects of structure and action of molluscan neuropeptides. Experientia 48:448-456.

Muneoka Y, Fujisawa Y, Matsuura M, Ikeda T (1991) Neurotransmitters and neuromodulators controlling the anterior byssus retractor muscle of Mytilus edulis. Comp Biochem Physiol 98C:105-1 14.

Nelson MT, Standen NB, Brayden IE, Worley JF (1988) Noradrenaline contracts arteries by activating voltage-dependent calcium channels. Nature 336:382-385.

Ocorr KA, Byrne JH (1986) Evidence for separate receptors that mediate parallel effects of serotonin and small cardioactive peptide ${ }_{\mathrm{B}}\left(\mathrm{SCP}_{\mathrm{B}}\right)$ on adenylate cyclase in Aplysia californica. Neurosci Lett 70:283288.

Ono K, Delay M, Nakajima T, Irisawa H, Giles W (1989) Calcitonin gene-related peptide regulates calcium current in heart muscle. Nature 340:721-724.

Paupardin-Tritsch D, Hammond C, Gerschenfeld HM (1986) Serotonin and cyclic GMP both induce an increase of the calcium current in the same identified molluscan neurons. J Neurosci 6:2715-2723.

Pellmar TC (1984) Enhancement of inward current by serotonin in neurons of Aplysia. I Neurobiol 15:13-25.

Probst WC, Cropper EC, Hooper SL, Kupfermann I, Weiss KR (1992) Convergent peptidergic phosphorylation of proteins in the ARC muscle of Aplysia. Soc Neurosci Abstr 18:1104.

Pucéat M, Terzic A, Clément O, Scamps F, Vogel SM, Vassort G (1992) Cardiac $\alpha_{1}$-adrenoceptors mediate positive inotropy via myofibrillar sensitization. Trends Pharmacol Sci 13:263-265.

Ram JL, Parti R (1985) Regulation of calcium influx into buccal muscles of Aplysia by acetylcholine and serotonin. J Neurobiol 16: $57-68$.

Ram JL, Patel S (1989) Skinned muscle fibers of Aplysia: potentiation of contraction by "background" calcium and lack of effect of cyclic AMP. Comp Biochem Physiol 93A:745-749.

Ram JL, Ajimal GS, Gole D, Haller KA, Williams A (1984a) Serotonin and forskolin enhance both magnitude of contraction and relaxation rate of $A p l y s i a$ dorsal extrinsic muscle independently of acetylcholine receptor. Comp Biochem Physiol 79C:455-459.

Ram JL, Shukla UA, Parti R, Goines RL (1984b) Extracellular calcium dependence of contracture and modulation by serotonin in buccal muscle E1 of Aplysia. J Neurobiol 15:197-206.

Ram JL, Zhang F, Liu L-X (1991) Contraction, setotonin-elicited modulation, and membrane currents of dissociated fibers of Aplysia buccal muscle. Biol Bull 180:276-283.

Rosenthal W, Hescheler J, Trautwein W, Schultz G (1988) Receptorand $G$-protein-mediated modulations of voltage-dependent calcium channels. Cold Spring Harbor Symp Quant Biol 53:247-254.

S-Rózsa K (1984) The pharmacology of molluscan neurons. Prog Neurobiol 23:79-150.

Sawada M, Ichinose M, Ito I, Maeno T, McAdoo DJ (1984) Effects of 5-hydroxytryptamine on membrane potential, contractility, accumulation of cyclic AMP, and $\mathrm{Ca}^{2+}$ movements in anterior aorta and ventricle of Aplysia. J Neurophysiol 5 1:361-374.

Scott RH, Pearson HA, Dolphin AC (1991) Aspects of vertebrate neuronal voltage-activated calcium currents and their regulation. Prog Neurobiol 36:485-520.

Sperelakis N (1988) Regulation of calciunn slow channels of cardiac muscle by cyclic nucleotides and phosphorylation. J Mol Cell Cardiol 20[Suppl II]:75-105.

Strong JA, Fox AP, I'sien RW, Kaczmarek LK (1987) Stimulation of protein kinase $\mathrm{C}$ recruits covert calcium channels in Aplysia bag cell neurons. Nature 325:714-717.

Tsien RW (1987) Calcium currents in heart cells and neurons. In: Neuromodulation (Kaczmarek LK, Levitan IB, eds), pp 206-242. New York: Oxford IJP.

Twarog BM, Muneoka Y (1972) Calcium and the control of contraction and relaxation in a molluscan catch muscle. Cold Spring Harbor Symp Quant Biol 37:489-503.

van Breemen $\mathrm{C}$, Saida $\mathrm{K}$ (1989) Cellular mechanisms regulating $\left[\mathrm{Ca}^{2+}\right]_{i}$ smooth muscle. Annu Rev Physiol 51:315-329.

Vilim FS, Price DA, Lesser W, Kupfermamn I, Weiss KR (1991) Direct measurement of peptide co-transmitter release following intracellular stimulation of a single identified motor neuron in Aplysia. Soc Neurosci Abstr 17:1305.

Vilim FS, Price DA, Kupfermann I, Weiss KR (1992) Modulation of peptide co-transmitter release from B15 neuromuscular junctions of Aplysia. Soc Neurosci Abstr 18:1104.

Vivaudou MB, Clapp LH, Walsh JV, Singer JJ (1988) Regulation of one type of $\mathrm{Ca}^{2+}$ current in smooth muscle cells by diacylglycerol and acetylcholine. FASEB J 2:2497-2504.

Watson WH, Groome JR (1989) Modulation of the Limulus heart. Am Zool 29:1287-1303.

Weiss KR, Cohen JL, Kupfermann I (1978) Modulatory control of buccal musculature by a serotonergic neuron (metacerebral cell) in Aplysia. J Neurophysiol 41:181-203.

Weiss KR, Mandelbaum DE, Schonberg M, Kupfermann I (1979) Modulation of buccal muscle contractility by serotonergic metacerebral cells in Aplysia: evidence for a role of cyclic adenosine monophosphate. J Neurophysiol 42:791-803.

Weiss KR, Březina V, Cropper EC, Hooper SL, Miller MW, Probst WC, Vilim FS, Kupfermann I (1992) Peptidergic co-transmission in Aplysia: functional implications for rhythmic behaviors. Experientia $48: 456-463$.

Whim MD, Lloyd PE (1989) Frequency-dependent release of peptide cotransmitters from identified cholinergic motor neurons in Aplysia. Proc Natl Acad Sci USA 86:9034-9038

Zoran MJ, Haydon PG, Matthews PJ (1989) Aminergic and peptidergic modulation of motor function at an identified neuromuscular junction in Helisoma. J Exp Biol 142:225-243. 